\title{
Blood Flow Dynamics in Burns
}

\section{Robin Mirdell}




\title{
Blood Flow Dynamics in Burns
}

\author{
Robin Mirdell
}

Department of Clinical and Experimental Medicine Institution of Medical and Health Sciences

Linköping University

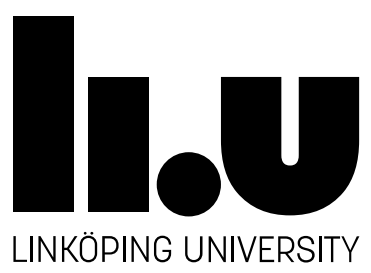


Blood flow dynamics in burns

(C) Robin Mirdell, 2019

robin.mirdell@liu.se

ISBN: 978-91-7929-945-3

ISSN: 0345-0082

Printed in Linköping, Sweden 2019

Liu-Tryck AB 
To research is to develop a limited understanding of an infinitesimal object on the mosaic of infinity. 



\section{Abstract}

Objectives:

Burns of intermediate thickness are hard to evaluate clinically. This often leads to unnecessary delays of up to 14 days before a surgical decision can be made. To counter this, several objective methods have been developed to determine the healing potential of the wound. Over the years, measurement of perfusion has proven to be the most successful method for evaluation of healing potential. Laser Doppler imaging (LDI) is currently the most used method and can determine surgical need 2 days after injury with an accuracy $>90 \%$.

There are however emerging techniques like laser speckle contrast imaging (LSCI), which also measure perfusion. LSCI have several advantages over LDI and is easier to use. LSCI can also investigate aspects of the microcirculation, previously not possible with LDI. The aim of this thesis was to investigate LSCI's ability to evaluate surgical need in burns of indeterminate partial-thickness.

The first objective was to investigate the dynamics of perfusion the first 14 days after injury. The purpose was to find the optimal time-window for perfusion measurements. The next goal was to determine the accuracy of different perfusion cutoffs. In this second study, the benefit of a subsequent measurement was also investigated. After this, interobserver variation between different profession groups was studied. Both the agreement of perfusion measurements and observer assessments were evaluated. Finally, cardiac vasomotion in combination with perfusion (pulsatility) was investigated as a method to determine surgical need $<48$ hours after injury.

\section{Methods:}

Perfusion was measured in a total of 77 patients at the Department of Plastic Surgery, Hand Surgery and Burns at Linköping University Hospital, Sweden. Most of these patients were children and the most common type of burn was scalds. A laser speckle contrast imager (PeriCam PSI System, Perimed AB, Järfälla, Sweden) was used to measure perfusion.

Results:

In the first paper we showed a clear relation between perfusion dynamics and the healing potential of the wound. The changes in perfusion were largest the first 5 days after injury, why this time interval was selected for subsequent papers. Perfusion measurements done day 3-4 after injury could predict surgical need with a sensitivity of $100 \%$ (95\% CI: $83.9-100 \%$ ) and a specificity of $90.4 \%$ (95\% CI: $83.8-94.9 \%$ ). If two measurements were used, $<24$ hours and 3-4 days after injury, the accuracy was $100 \%$. Furthermore, we found that different observers could consistently predict 
perfusion, while there was a large variation in their clinical assessments. This was not improved by extensive burn experience. Finally, pulsatility could be used to predict surgical need the same day as the injury occurred with a sensitivity of 100\% (95\% CI: $88.1-100 \%)$ and a specificity of $98.8 \%$ (95\% CI: $95.7-99.9 \%)$.

\section{Conclusions:}

LSCI is a promising method for evaluation of burns and provides several benefits over LDI. The surgical need of burns can be determined mere hours after injury when pulsatility is measured. However, the benefits of early scald diagnostics in children with LSCI need to be evaluated in a prospective study before the method is ready for routine clinical use. 


\section{Populärvetenskaplig sammanfattning}

Uppskattningsvis sker ca 38000 (0,4\% av befolkningen) vårdkontakter i Sverige årligen pga. brännskador. Det finns flera orsaker till brännskador och de kan delas upp i olika kategorier såsom flam-, kemisk, elektrisk, kontakt- och skållningsbrännskada. Bland barn är den vanligaste orsaken skållning följt av kontaktbrännskador (spisolyckor etc.).

De flesta skador är ganska lindriga men vissa patienter drabbas av djupa skador som läker först efter tre veckor och då krävs kirurgi för ett gott resultat. Trots kirurgi har djupa skador en ökad risk för kraftig ärrbildning och sammandragningar i huden. Tiden det tar för skador att läka har visats vara starkt kopplad till skadans djup och risken för komplikationer på lång sikt. Det är därför viktigt att påskynda läkningsprocessen. Tidig kirurgi hos patienter med djupa brännskador har i studier visat ett förbättrat slutresultat i form av lindrigare ärrbildning. Tanken är att läketid förkortas i och med ett tidigt ingrepp.

I dagsläget görs djupbedömning av skador genom att kliniskt undersöka kapilläråterfyllnad, skadans utseende och patientens känsel. Detta leder till en korrekt bedömning av skadans djup i $60 \%$ av fallen tre dagar efter skadan. Klinisk bedömning kring operationsbehov har en god träffsäkerhet först åtta dagar efter skadetillfället. Ofta finns dock flertalet skadeområden som fortsatt kan vara svårbedömda. För att säkert veta vad som behöver opereras behöver man då vänta ytterligare. När operationen väl utförts tar det ytterligare 5-10 dagar innan delhudstransplantatet har läkt.

Varje dag som såren är öppna finns en risk för att patienten drabbas av en infektion som t.o.m. kan orsaka blodförgiftning. När såren är öppna behöver de också läggas om var 2-3:e dag. Vid varje omläggning måste såren tvättas och förbanden bytas. Detta är en mycket smärtsam process och innebär att patienten måste få kraftig sedering eller sövas. Så länge patient har öppna sår finns också en ökad risk för vårdrelaterade infektioner. Ett sår som inte läker fort innebär ett omfattande lidande för patient, risk för komplikationer men också höga kostnader för vården.

I nuläget finns flertalet optiska metoder som kan utvärdera brännskador och fastställa vad som behöver opereras. Dessa metoder har fokuserat på att uppskatta blodflöde som ett surrogatmått på hur djup brännskadan faktiskt är. Detta surrogatmått kallas för perfusion och har en stark koppling till det faktiska blodflödet i vävnaden. Den äldsta och mest använda metoden heter laser Doppler imaging (LDI) och använder sig av Dopplereffekten för att mäta perfusionen i skadorna. Tekniken är dock klumpig och kräver lång tid för att man ska kunna utvärdera perfusionen i hela brännskadan. Däremot har LDI kunnat visa en träffsäkerhet på ca $90 \%$ från och med 2 dagar efter skadetillfället vilket ger ett gott underlag för att planera en operation. 
Laser speckle contrast imaging (LSCI) är en nyare teknik än LDI och bygger också på laserljus. LSCI mäter perfusion genom att mäta hur laserns interferensmönster suddas ut genom rörelse av röda blodkroppar. Fördelen med LSCI är att man kan avbilda stora områden på millisekunder istället för ca 4-12 sekunder som för LDI. Samtidigt har LSCI också bättre optisk upplösning. Än så länge har LSCI huvudsakligen använts för att undersöka brännskador i djurmodeller. Det finns därför ett stort behov av att utvärdera hur metoden fungerar hos riktiga patienter.

Avhandlingen består av fyra delarbeten där flertalet aspekter av LSCI har undersökts. Huvudsyftet har varit att kunna använda metoden för att identifiera skador med ett operationsbehov så tidigt som möjligt.

Målet med det första arbetet var att undersöka hur perfusionen förändras i brännskador de första dagarna efter olyckan. Syftet var att fastställa bästa dagen att mäta på och om man kunde använda sig av förändringar mellan olika dagar för att få fram bättre modeller.

Arbete nummer två hade ett större patientmaterial och målsättningen var att hitta perfusionsgränsvärden för operationsbehov. I detta arbete kunde vi fastställa att metoden blev säkrare om man hade två mätningar, den första inom 24 timmar och den andra 3-4 dagar efter skadetillfället.

I det tredje arbetet undersöktes hur olika observatörer, med varierande erfarenhet av brännskador, använde sig av LSCI-bilder för att bedöma operationsbehov. Bedömningsdelen visade sig vara svår, däremot kom alla observatörer fram till liknande perfusionsvärden. Slutsatsen var att LSCI-användare behöver gedigen erfarenhet av metoden för att tolka perfusionvärdena på rätt sätt.

Det fjärde och sista arbetet riktade in sig på att undersöka de kortvariga perfusionsförändringarna som uppstår under hjärtats cykel. Målsättningen var att ännu tidigare kunna avgöra operationsbehov. LSCI användes istället som en videokamera och perfusionsinspelningar gjordes av hela skadan. Perfusionsförändringarna visade sig var mindre och mer kaotiska i djupa skador. Detta får tolkas som ett tidigt tecken på störningar av blodflödet. Med denna metod kunde skadans operationsbehov bedömas med nära $100 \%$ träffsäkerhet samma dag som den inträffat.

Sammanfattningsvis har slutsatserna från avhandlingen utvecklat LSCI så långt att man snart kan använda metoden inom högspecialiserad brännskadevård. Detta skulle leda till tidigare operationer, minskade kostnader och framförallt ett minskat lidande hos en stor patientgrupp. 


\section{Supervisor}

Erik Tesselaar, Associate Professor

Department of Clinical and Experimental Medicine, Division of Surgery, Orthopedics and Oncology, Linköping University, Sweden.

\section{Assistant supervisors}

Simon Farnebo, Associate Professor, MD

Department of Clinical and Experimental Medicine, Division of Surgery, Orthopedics and Oncology, Linköping University, Sweden.

Folke Sjöberg, Professor, MD

Department of Clinical and Experimental Medicine, Division of Surgery, Orthopedics and Oncology, Linköping University, Sweden.

\section{Opponent}

Paul van Zuijlen, Professor, MD

Dutch Burn Center, Beverwijk, The Netherlands.

\section{Faculty board}

Olle Stendahl, Professor Emeritus

Department of Clinical and Experimental Medicine, Division of Microbiology, Infection and Inflammation, Linköping University, Sweden.

Emma Hansson, Associate Professor, MD

Department of Plastic Surgery at Institute of Clinical Sciences, Sahlgrenska University Hospital, Gothenburg, Sweden.

Ingemar Fredriksson, Adjunct Senior Lecturer

Department of Biomedical Engineering (IMT), Division of Biomedical Engineering (MT), Linköping University, Sweden.

\section{Suppleant}

Håkan Pettersson, Associate Professor

Department of Medical and Health Sciences (IMH), Division of Radiological Sciences (RAD), Linköping University, Sweden. 



\section{List of original papers}

This thesis is a summary and discussion of the results obtained in the following papers:

\section{Paper I}

Robin Mirdell, Fredrik Iredahl, Folke Sjöberg, Simon Farnebo, and Erik Tesselaar.

Microvascular blood flow in scalds in children and its relation to duration of wound healing: A study using laser speckle contrast imaging.

Burns. 2016 May;42(3):648-54.

\section{Paper II}

Robin Mirdell, Simon Farnebo, Folke Sjöberg, and Erik Tesselaar.

Accuracy of laser speckle contrast imaging in the assessment of pediatric scald wounds.

Burns. 2018 Feb;44(1):90-98.

\section{Paper III}

Robin Mirdell, Simon Farnebo, Folke Sjöberg, and Erik Tesselaar.

Interobserver reliability of laser speckle contrast imaging in the assessment of burns. Burns. 2019 Sep;45(6):1325-1335.

\section{Paper IV}

Robin Mirdell, Simon Farnebo, Folke Sjöberg, and Erik Tesselaar.

Pulsatility in burns using laser speckle contrast imaging Manuscript, submitted to Burns. 



\section{List of abbreviations}
AU - Arbitrary units
CI - Confidence interval
$\mathrm{CV}$ - Coefficient of variation
ICC - Intraclass correlation
LDF - Laser Doppler flowmetry
LDI - Laser Doppler imaging
LSCI - Laser speckle contrast imaging
NPV - Negative predictive value
PPV - Positive predictive value
PU - Perfusion units
$\mathrm{PU}^{2}-$ Pulsatility
ROC - Receiver operator characteristics
ROI - Region(s) of interest
SD - Standard deviation

TBSA - Total body surface area 



\section{Table of Contents}

List of original papers

List of abbreviations

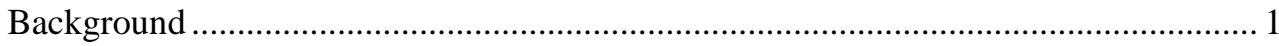

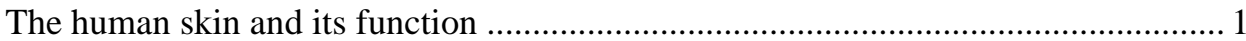

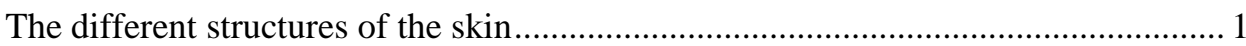

Burn categories in Sweden and in the world ......................................................... 3

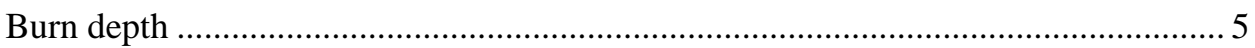

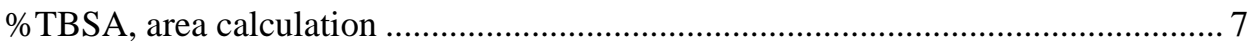

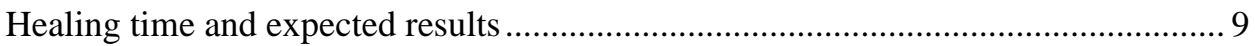

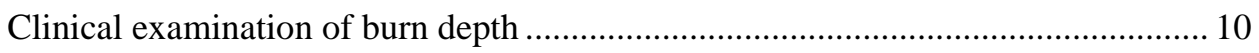

Objective methods for burn depth assessment ...................................................... 11

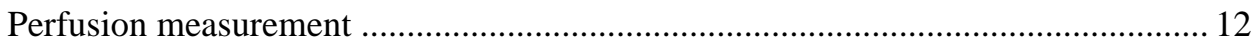

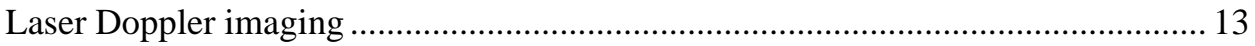

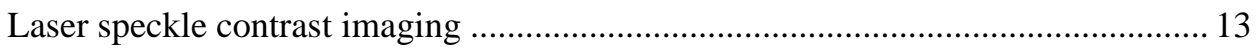

Summary of current perfusion research in burns .................................................. 18

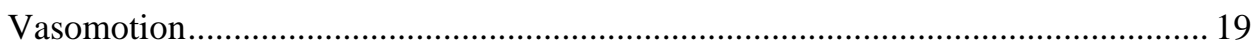

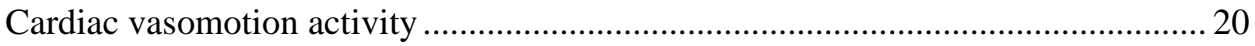

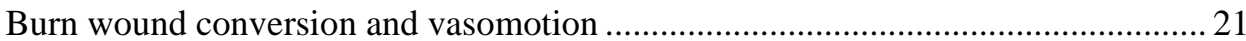

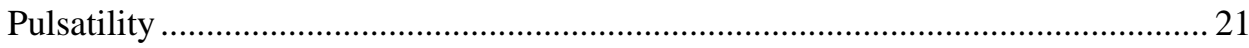

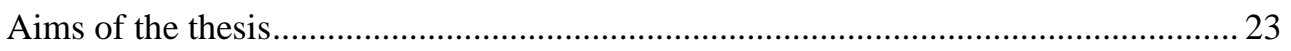

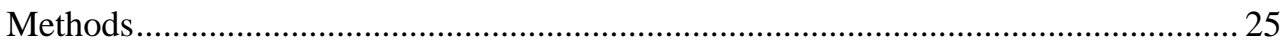

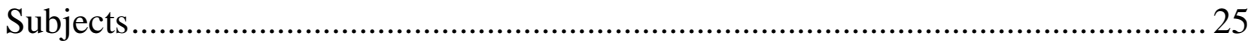

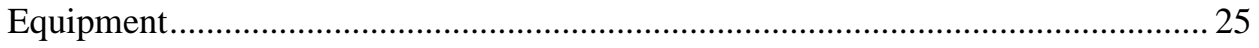

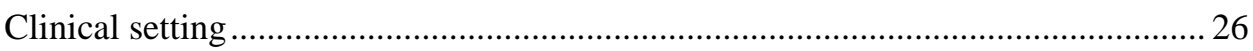

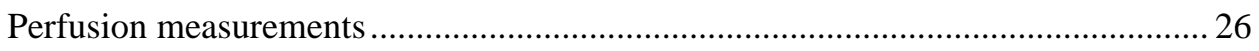

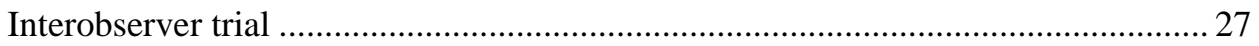

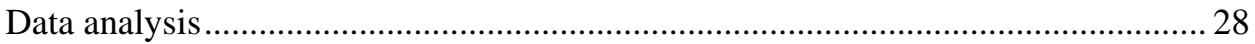

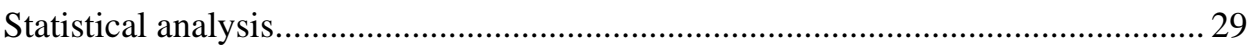

Paper I: ...................................................................................... 30

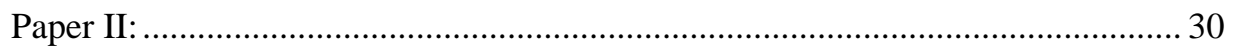

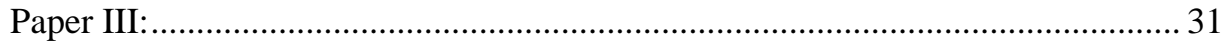

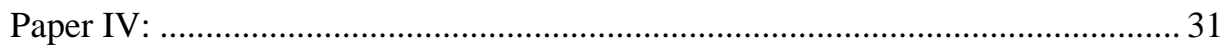




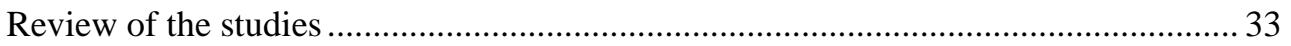

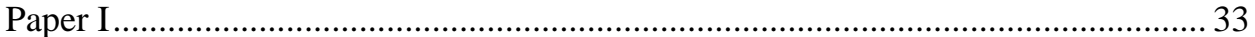

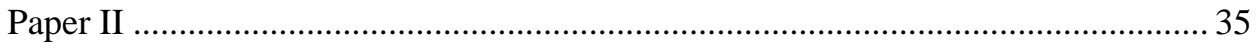

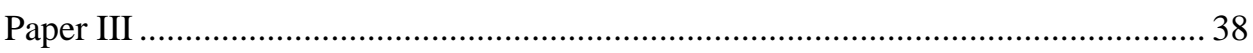

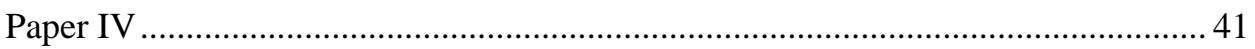

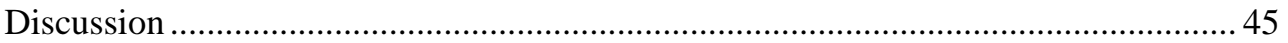

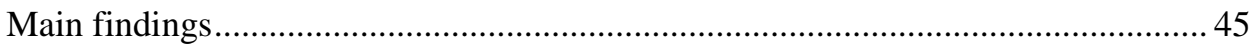

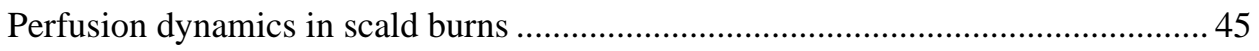

Single measurement and double measurement to determine surgical need ............. 46

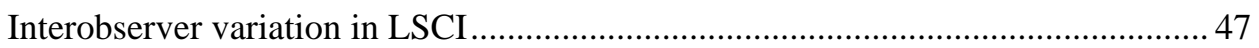

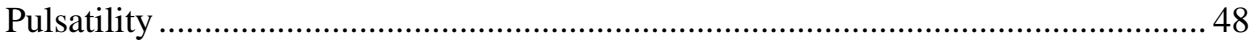

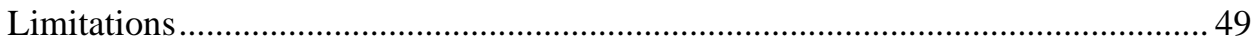

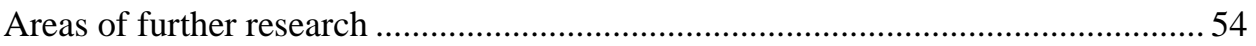

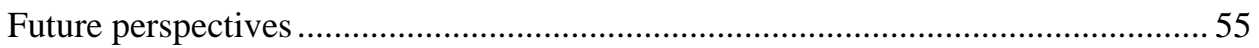

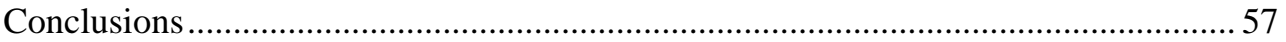

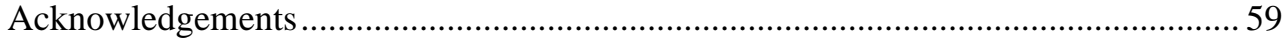

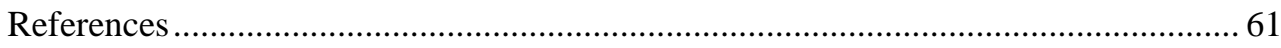

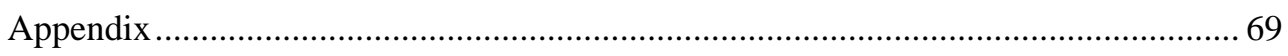

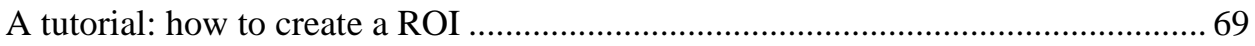

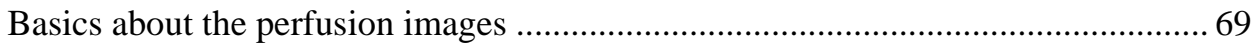

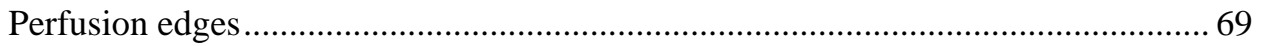

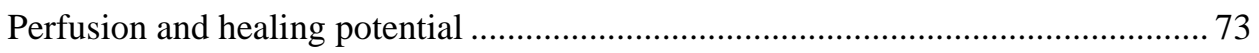

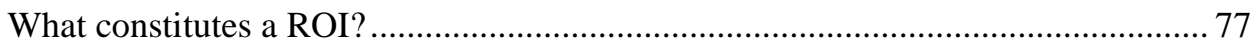

Development of different methods for evaluation of perfusion images.................. 78

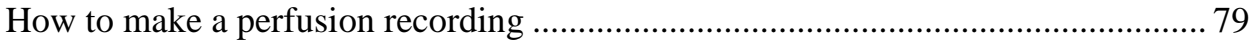

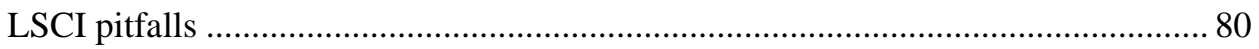

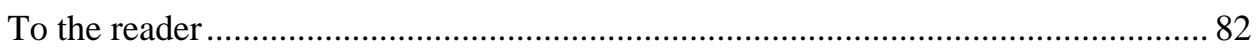

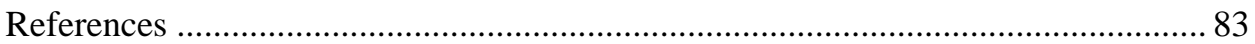




\section{Background}

\section{The human skin and its function}

The skin is often described as the largest organ in humans [1]. Its primary function is as a barrier and to create the internal milieu required for all advanced life forms [2]. This barrier function has several subcomponents. The first function is to work as an osmotic barrier towards the external milieu [2]. The second function is to protect from infiltration of microorganisms, both pathogens and commensals [2]. A third function is heat regulation, where the skin provides natural insulation but can also facilitate heat loss through sweat glands, hair, and convection [2,3]. A fourth function is to protect from harmful radiation, primarily UV-light which would otherwise causes DNAdamage [3]. A fifth function is to provide sensory input in form of touch, pressure, pain, heat, cold, and degree of moisture [4]. The skin also has an important metabolic function and stores much of the body's energy reserve in the hypodermis [2]. Finally, the skin also has an important esthetic function.

To summarize, the skin has a lot of functions and without an intact skin barrier it is not possible to survive. The skin also provides several functions, which are required to have normal bodily functions, to avoid harm, to work, and to do everyday activities.

\section{The different structures of the skin}

The skin is made up of three primary layers where further subdivisions can be made [1-3]. A schematic description of the skin is shown in figure 1.

The outermost layer is the epidermis, which in turn consists of five layers from outermost to innermost: stratum corneum, stratum lucidum (glabrous skin), stratum granulosum, stratum spinosum, and stratum basale [1]. All cell division occurs in stratum basale and the primary cell type is the keratinocytes [1]. In this layer we also find melanocytes, Langerhans cells, and Merkel cells which provide important functions in form of pigmentation, immunogenic defense, and sensory information, respectively [1]. If the stratum basale is removed, recreation of the epidermis is no longer possible, and healing has to occur through migration of cells from adjacent areas [5]. The epidermis also extends down into hair follicles and sweat glands [5]. This can facilitate reepithelialization when the epidermis is removed from an area, but these small skin reserves remain [5]. The epidermis does not contain any other structures and is avascular. Nutrients are delivered by diffusion from 
the dermis and the papillary loops [6]. The primary function is to provide an outer shield and it is also important from an immunogenic point of view.

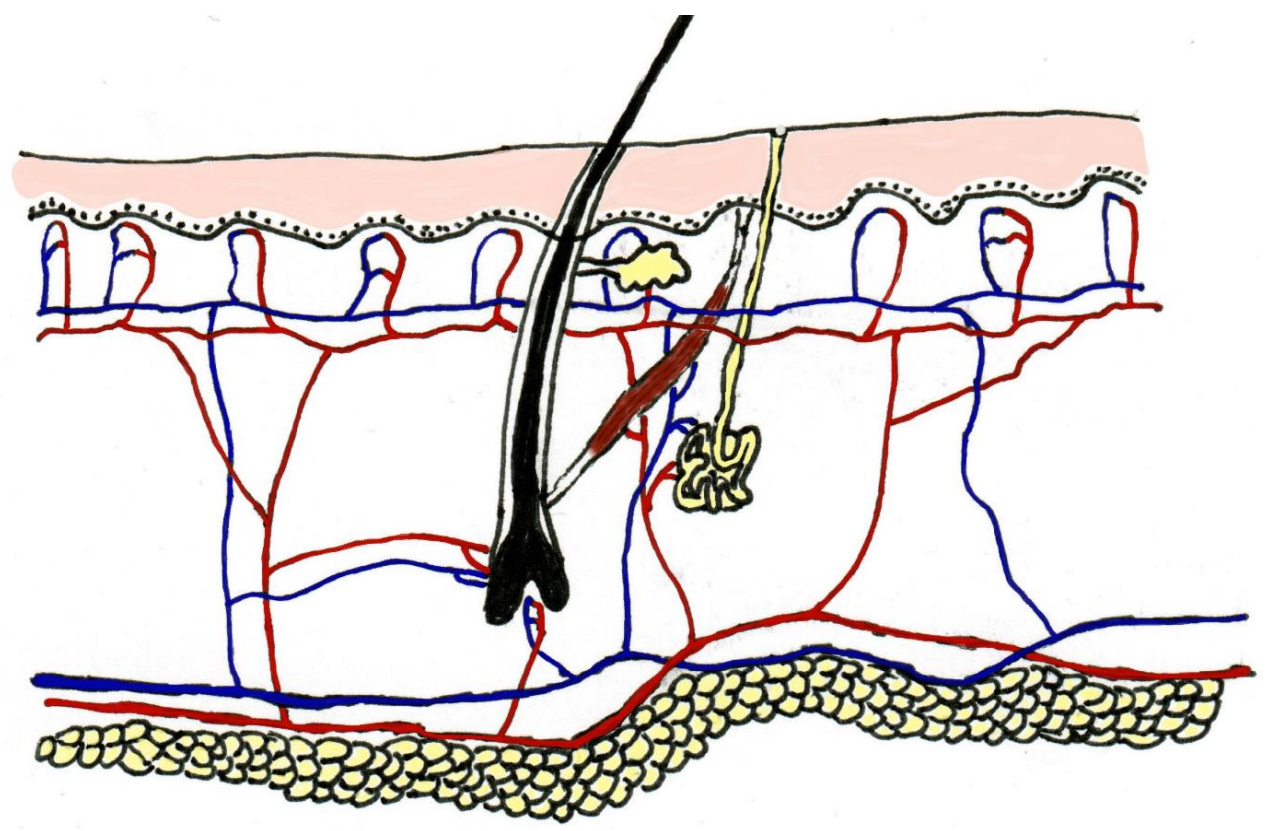

Figure 1. Schematic image of the different structures of the skin. The upper pink part shows the epidermis with stratum basale illustrated as small dots. Beneath is the dermis and its vascular supply depicted with blue (venules) and red (arterioles). In the center of the image is a hair follicle which contain potential epidermal progenitor cells. In connection to the hair, there is an arrector pili muscle and a sebaceous gland. An eccrine sweat gland can be seen to the right of the hair. The bottom part of the image depicts the hypodermis and its subcutaneous fat tissue.

Deeper into the skin we have the dermal layer which can be further divided into an inner layer of reticular dermis and an outer layer of papillary dermis [1-3]. In many ways the dermal layer is more interesting than the other layers since it contains most of the skin's structures. In the reticular dermis we will find most of the hair follicles (some are hypodermal), eccrine/apocrine sweat glands, Meissner's corpuscle, and free nerve endings [1-4]. Ruffini corpuscles are also found in the deeper parts of the reticular dermis which are important to detect stretching of the tissue [4]. There is also a high density of capillaries in the dermis and most of the skin's capillary density will be found here [6]. The microcirculation is divided into two different vascular plexuses [6]. The most superficial plexus is in the papillary dermis and extends along the dermal papillae forming ridges into the epidermis providing nutrients for the stratum basale of the epidermis and superficial sensory nerves [6]. The second plexus is in the 
reticular dermis and consist of slightly larger vessels and many of the skin's arteriovenous shunts [7]. There are also interconnecting vessels between the two plexuses, but the area between the two plexuses has a lower vascular density than the rest of the dermis [6]. The superficial plexus primarily has a nutritive role in the skin, while the deeper plexus also provides a heat regulatory function [6]. The primary function of the dermis is to provide tensile strength to the skin, sensory functions, heat regulation, and nutrition to support these functions.

The last innermost layer of the skin is the hypodermal or subcutaneous layer which is the thickest layer and consists mainly of adipocytes [3]. Some structures such as hair follicles and sweat glands are occasionally found here [3]. Sensory structures in form of Pacinian corpuscles are also found here which are important for detecting pressure and vibration [4]. The capillary density is low in this layer of the skin, but perforating vessels are common here which supply the overlying dermis [6]. The most important function of the hypodermis is insulation, but it also provides the rest of the body some protection from blunt trauma and contributes to metabolic regulation through its energy reserves [3].

There are also substantial variations in skin structures depending on the anatomical position of the skin. Stratum lucidum for example is only present in glabrous skin of the soles and palms. The density of sensory structures varies a lot depending on the localization of the skin, with a high degree of precision in digits for example [4]. The thickness of the different skin layers also has a high degree of variation with skin thinner than $1 \mathrm{~mm}$ in the eyelids and thicker than $5 \mathrm{~mm}$ in the back [8]. The variation in thickness also seems to correlate to other aspects such as local capillary density. The skin therefore must be regarded as a heterogenous organ where knowledge about these anatomical variations sometimes is essential.

\section{Burn categories in Sweden and in the world}

It is estimated that roughly 38,000 burns occur annually in Sweden [9]. Burns have a higher incidence in low income countries and are estimated to cause as many as 300,000 deaths annually in the world [9]. Around 90\% of all burns occur in low and middle-income countries [9]. The range in burn severity is large, however. Most burns are superficial and affect a very small percentage of the skin, while extensive burns often constitute a life-threatening condition.

Burns are divided into different categories depending on the causing agent [10]. Typically, the following categories are used: thermal burn (scald/contact/flame), 
chemical burn, and electrical burn [10]. The type of burn decides the best clinical approach and affect the damage pattern on both a macroscopic and histological level.

A scald is a quite broad category as the proper definition is a burn sustained from any form of liquid or gas. The most common scald is however: boiling water, recently boiled water for cooking purposes, hot coffee, or hot tea. Therefore, scalds are generally caused by water at a temperature of $80-100{ }^{\circ} \mathrm{C}$, which was spilled in an accidental manner. The wounds are mostly superficial, but 10 to $20 \%$ of the patients may have areas with deeper burns. Scalds are common worldwide, and the typical patient is a 1-5-year-old child [9]. Occasionally, scalds are also caused by heated oil, which cause deeper burns because of the higher temperature. The best way to treat scalds is through primary prevention and much work has been focused on this with a decreased incidence over time reported in many countries $[9,11]$.

Contact burns constitutes another large category. These primarily occur in the same patient group as scalds [11]. The body part commonly affected is the palmar aspect of the hand. The wounds are generally accidental, occurring through direct contact with a hot object like a stove. The combination of thick skin, high capillary density, and good sensory function often protects from deeper injuries and most of these burns can be treated conservatively and seldom requires surgery.

Depending on country, flame burns are quite uncommon but is the most common cause of fatal burns or burns causing substantial morbidity [9, 10]. Generally, these patients have large areas that are apparent full thickness burns [10]. A substantial part of the burn is often partial-thickness and may therefore have the potential to heal spontaneously. Several sessions in the operating theater are usually required, leading to an extended hospital stay which makes it a large patient group in any burn center [10].

Chemical burns often behave quite like scalds, but there is a wide range on the exact behavior related to which chemical compound caused the burn [12]. Many chemical burns are also caused by a heated agent which will often have similar convective properties to water. Chemical burns are most frequently caused by alkalis but in some geographic areas, acids are the leading cause [12,13]. Previously chemical burns were primarily caused by accidents in the industry, but domestic accidents are becoming more common [13]. Depending on the causing agent, different washing regimes can be used to rinse out the chemical compound that has already permeated the skin $[12,13]$.

Electrical burns are different from the other burn categories. In most cases, the visual skin burns are quite small and there is usually an entry and an exit burn correlating to the passage of the current. However, there might be extensive damage 
on other parts of the body, which should always be considered when electrical burns are treated [14].

\section{Burn depth}

Traditionally burns have been divided into $1^{\text {st }}, 2^{\text {nd }}$, and $3^{\text {rd }}$ degree [15]. However, nowadays the most used nomenclature are the following terms: superficial $\left(1^{\text {st }}\right)$, superficial partial-thickness $\left(2^{\text {nd }}\right)$, deep partial-thickness $\left(2^{\text {nd }}\right)$, and full thickness burn $\left(3^{\text {rd }}\right)$ [16-18]. One reason for this new nomenclature is the large difference in clinical approach to superficial partial-thickness burns and deep partial-thickness burns, where the latter generally requires surgery. A classical description of the different burn zones is shown in figure 2 .

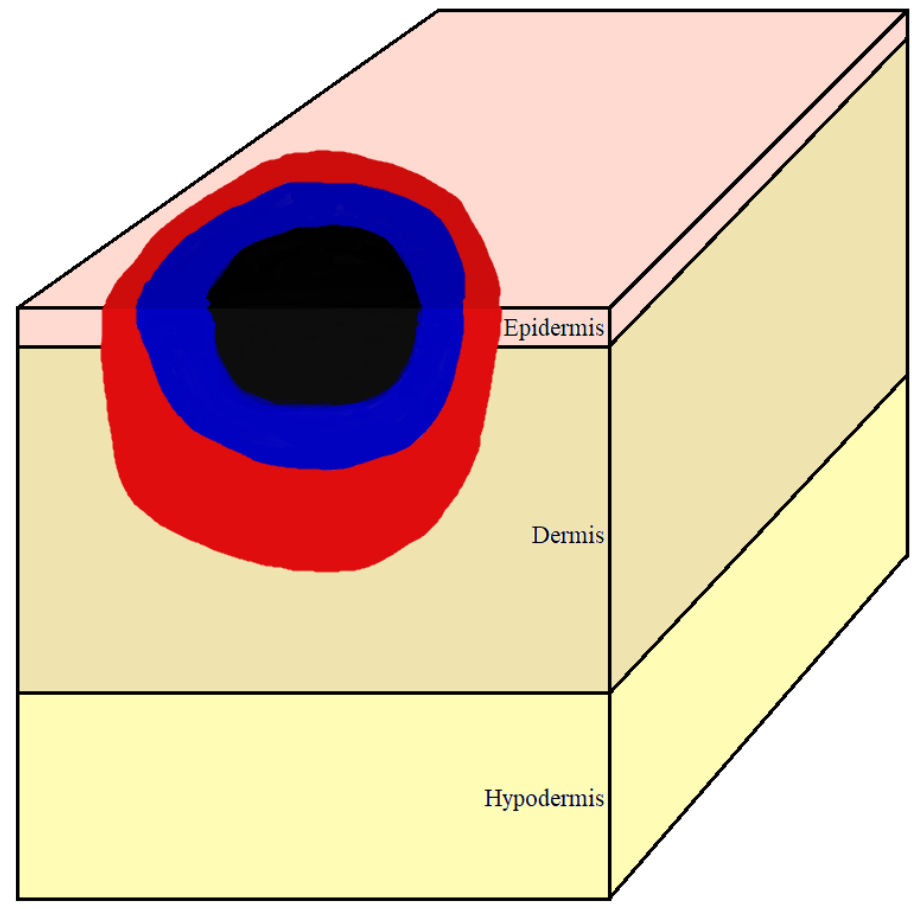

Figure 2. Shows a schematic image of the skin and the classic burn zones described by Jackson [19]. The different colored zones correspond to the following: black = zone of coagulation, blue = zone of stasis, red = zone of hyperemia. The zone of coagulation is already lost, but the zone of stasis can still be recovered or continue towards necrosis. 
Superficial burns only affect the outermost layer of the skin (epidermis) and can be compared to a sunburn [16-18]. The skin turns red, but the barrier function is still intact which means there will be no fluid leakage from the wounded area. Typically, this burn requires only symptomatic treatment. In clinical practice, superficial burns are not included when calculating the area of the burn [16-18]. This make it more difficult to accurately assess the size of the burn, as most severe burns often have large surrounding areas of superficial burns, potentially leading the inexperienced observer astray.

Superficial partial-thickness burns extend through the entire epidermis and have affected the underlying dermal component to some degree $[8,10,17]$. Generally, the papillary dermis will be somewhat damaged, and the damage often extends down to the reticular dermis with possible damage to many of its structures. There will always be substantial fluid leakage as the barrier function of the epidermis has been disabled. This will cause the epidermis to slough and it often falls off shortly after the injury. Sometimes the epidermis is only slightly detached, which later causes blister formation. The blisters may break with time, exposing the underlying wound. Sensory functions are intact and many free nerve endings are directly exposed to the surrounding environment. Superficial partial-thickness burns are therefore very sensitive to touch and will trigger a sharp pain response during a dressing procedure $[8,10,17]$. Since the superficial vascular plexus is mostly intact, these burns will appear red to pink in color and when the capillary refill time is tested it will appear quick $[8,10,17]$. The healing time is usually between 5 to 12 days, but the burn should always be considered superficial partial-thickness if reepithelialized within 14 days $[8,10,17]$.

Deep partial-thickness burns extend through most of the reticular dermis and will often display substantial damage to the different dermal structures $[8,10,17]$. There will be some fluid leakage but often reduced compared to the more superficial partialthickness burns. The superficial vascular plexus is often severely damaged, while the deeper vascular plexus might be quite preserved. Many of the free nerve endings will also have been damaged, meaning that the pain response is dulled $[8,10,17]$. The color of these burns is often paler, and the capillary refill time is often increased but capillary refill is still present $[8,10,17]$. Sometimes there will also be more complex color patterns with speckle like areas of deep red which do not blanch on pressure, suggestive of an underlying micro hematoma. As deeper structures of the dermis may be preserved, plenty of epidermal cells could still be alive and facilitate reepithelialization [5]. To what extent, is however difficult to establish. Reasonably, there is a high degree of correlation between preserved keratinocytes and remaining perfusion in the superficial vascular plexus. Deep partial-thickness burns require over 
14 days to heal and the typical range for spontaneous healing is between 3 to 8 weeks from the date of injury.

Full-thickness burns extend through both epidermis/dermis and affect the underlying hypodermis $[8,10,17]$. Almost all structures in the skin have therefore been destroyed. In most cases, the dead dermis will remain on top of the wound, but the skin will be dry as there is no circulation $[8,10,17]$. Typically, the skin will be pale or discolored without any capillary refill $[8,10,17]$. Most sensory function is gone and there are no keratinocytes for reepithelialization. Full-thickness burns always require surgery since healing is only possible through migration of adjacent tissue and healing by contracture of the skin $[8,10,17]$. Healing with contracture is very limited in humans but is the most important healing method for other species like mice [20]. The lack of contracture healing in humans is partly because we lack a panniculus carnosus, except for the skin area around the neck covered by the platysma [20].

\section{\%TBSA, area calculation}

To know the depth of a burn is important, but to know its area is more important as it determines fluid resuscitation calculations. Previously many patients died of even small burns due to septic shock and hypovolemia [15]. The most important factor that has improved survival in patients with extensive burns the last 80 years is the progress in early fluid resuscitation in combination with early excision [15]. The Parkland formula is commonly used, where the fluid requirement the first 24 hours is equal to 4 $\mathrm{ml} \times$ percentage of the total body surface area $(\%$ TBSA) $\times$ body weight $(\mathrm{kg})$ [15]. It is therefore essential to have a good estimate of the burn's extent and to treat other potentially more life-threatening conditions before attention is focused on healing the wounds.

Over the years, there have been several different methods for estimation of the \%TBSA. Remember that superficial (epidermal) burns are excluded from the calculations. The most notable guide for determining the \%TBSA is the Lund Browder chart (see figure 3), which has several versions depending on the age of the patient, as the surface area of limbs vary with age [22]. By using the chart, the surgeon can make a quick drawing of the wound and calculate the \%TBSA after the examination. The Lund Browder chart is regarded as quite precise and will give a result close to the true \% TBSA. However, this method still has a degree of interobserver variation. 

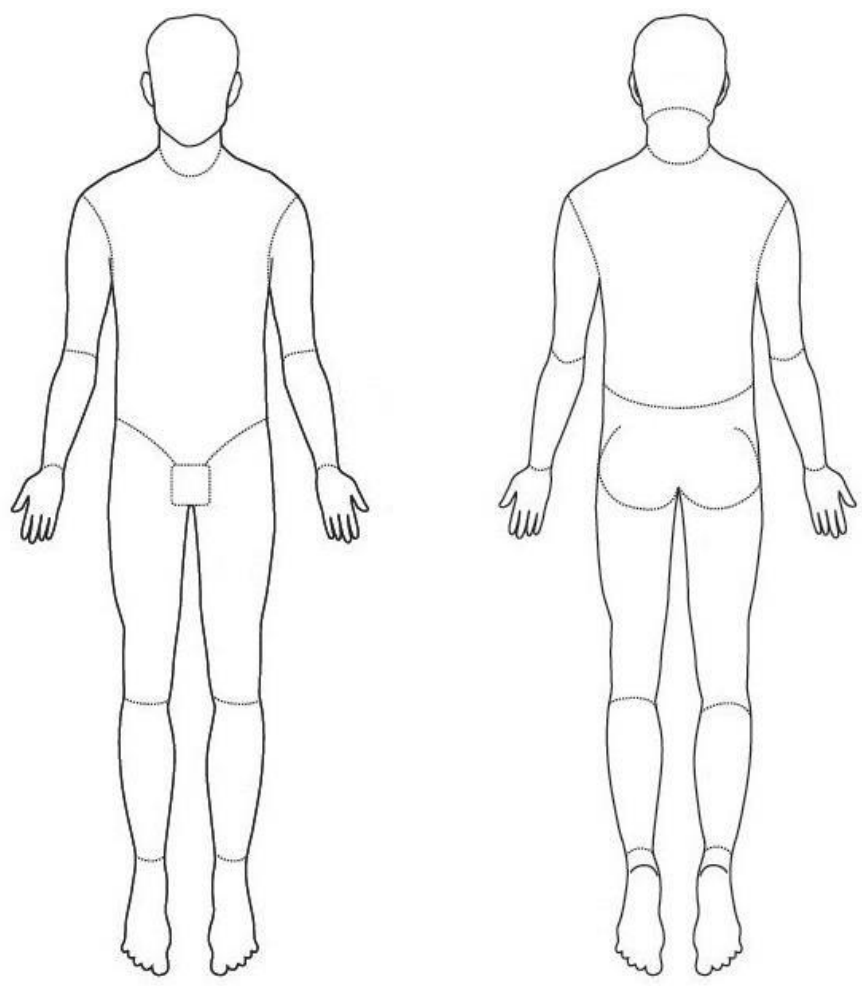

Figure 3. Example image of a Lund Browder chart. The patient's burn is examined, and the corresponding area is marked on the chart. All areas are then added together to arrive at the final \%TBSA.

Since filling out a Lund Browder chart requires a paper-form and a pencil, some surgeons prefer to do a quicker estimation, using the rule of nines. This rule is based on the estimate that the entire arm and hand of a grown individual is equal to $9 \%$ of the body surface [23]. The front side of the leg and foot is also $9 \%$, and the back of the leg 9\%. The front side of the torso is $18 \%$ and the back $18 \%$ [23]. The head is regarded to have a \%TBSA of $9 \%$ and finally there is $1 \%$ left for the genital area [23]. This method is very simple to use but is also associated with a higher degree of interobserver variation.

By using the rule of nines, an even simpler method was derived, the rule of palms. This method uses the fact that the palm is equal to roughly $1 \%$ TBSA. For obvious reasons, the patient's hand should always be used as a blueprint. The easiest approach is to compare the patient's palm to a similar sized object and then use the object to estimate the number of palms the burn consists of. It has been suggested that this leads 
to an overestimation of the \%TBSA, as the palm of the hand is much smaller than $1 \%$ TBSA. In a study it was shown that the size of the palm was on average $0.81 \%$ TBSA in men and $0.67 \%$ TBSA in women [24].

It should also be mentioned that several systems have been made to calculate the true \% TBSA based on camera images $[25,26]$. Although some success has been achieved, currently available systems are not routinely used. Easy to use methods to establish the exact \%TBSA would be welcome, as it is known that \% TBSA is predictive of the long-term outcome for the patient, even without any information about the burn depth [21,27].

\section{Healing time and expected results}

In the majority of patients, the burns will be of superficial partial-thickness and heal in 5-12 days [8, 10, 17]. These wounds sometimes contain areas of deep partial-thickness burns, which may require surgical intervention for optimal results. This intervention typically consists of excision and split-thickness skin grafting [8, 10, 21]. This means that the burn wound is mechanically removed tangentially, usually with a Watson knife or similar appliances. The tissue is removed in small slices at a time until a healthy wound bed is uncovered. Once this is done a transplant needs to be gathered, usually from the thigh or buttocks. Most often a dermatome is used for this procedure, which is an instrument that resembles an electric cheese slicer. Depending on the settings and pressure applied, different thickness can be achieved. A typical thickness is around 300 to 500 microns. The transplant is then meshed, often 1.5:1 and then attached to the prepared wound bed with staples or tissue glue.

Previous studies have shown that wounds which heal after 3 weeks are associated with a high risk (>40\%) for hypertrophic scarring, whereas wound healing between week 2 and 3 only have a moderate risk (20\%) [28]. It is therefore essential to identify these wounds at an early stage so surgery can be undertaken without delay. It is suspected that the time to wound closure is the most important aspect of scarring [28, 29]. In a hypothetical scenario: if a wound which would heal in 28 days was identified on day 2, wound closure could be achieved after an additional 5-7 days with splitthickness skin grafting. This would put the final healing time at 7-9 days. If surgery was done day 14 , when there is $100 \%$ certainty that the wound is deep partialthickness and that it is unlikely to heal within 3 weeks, the final healing time would be 19-21 days. The latter option is believed to increase the risk for hypertrophic scarring and is avoidable with an early and correct diagnosis of the actual burn depth [28, 29]. 
There is also a second patient group, which has extensive burns of different depths spread over the body. In these cases, it is important to prioritize which areas are in most need of surgery. The first few surgeries are often self-evident to the experienced surgeon, in form of areas with full-thickness burns. As the days go by and the deepest wounds undergo surgery, it becomes more difficult for the surgeon to understand which remaining areas might heal within a reasonable time frame and possibly avoid unnecessary surgery.

It is difficult to predict the outcome for a patient with more extensive burns, but much work has been done on models which attempt to do so [21, 27, 29]. The most important factor has always been the \%TBSA [27]. In addition to this, age has been identified as the other large risk factor [21,27]. This lead to the creation of the Baux score which is the sum of the \%TBSA and the age of the patient [21]. In the original paper, this sum had a high correlation to the actual mortality rate, where a score of 100 was called the point of futility [30]. For example, a patient aged 50 with 50\%TBSA would have a Baux score of 100 . Another patient aged 20 with $80 \%$ TBSA would also have a Baux score of 100. Even though the relative area of the burns is $60 \%$ larger in the second patient compared to first, they both have the same prognosis. The Baux score used to correlate quite well to the actual mortality rate, but because of improvements in burn care, the point of futility is now at a score of 160 [30].

\section{Clinical examination of burn depth}

A clinical examination is performed by letting an experienced surgeon investigate several qualities of the burn. The area of the burn must be calculated. It must also be established if some areas within the burn appear to be deeper. The color is investigated, the degree of moisture, blanching upon pressure, and potential patterns in the burns might be helpful $[8,10,17,31,32]$. The damage mechanism and exact localization of the burn might be essential for deciding surgical need. There is no standardized scoring system for clinical burn assessment and therefore the value ascribed to these different aspects is highly subjective.

Even though a clinical examination is simple to do, there are several issues with the subjectivity of the evaluation. The results will vary a lot if two different surgeons are asked to examine the same patients in a blinded fashion. Previous studies have shown that the accuracy compared to histology or actual outcome ranges between 60$75 \%$ for a clinical examination $0-5$ days after injury in partial-thickness burns $[31,33]$. Early intervention is therefore only possible in full-thickness burns, which are much easier to diagnose. The accuracy of a clinical examination however increases with time 
[33]. Most partial-thickness burns therefore need to be evaluated 2-3 times before a surgical decision can be made. Beyond day 8 after injury, clinical examination will approach $100 \%$ accuracy for determining surgical need in partial-thickness burns [33]. This means that a lot of time as already been lost however, even if surgery is done day 8.

\section{Objective methods for burn depth assessment}

The obvious alternative to a clinical examination is an objective method, based on a measurable physical quality which can be converted to a number or an image. Several objective methods have been suggested and tried for burn diagnostics [17, 31, 33-50]. An optimal method should be easy to use, non-invasive, and quick. It should also examine the entire burn to avoid potential sampling errors. It should not cause any discomfort for the patient or for the personnel using it. Preferably, the method should produce images that are easy to interpret and that can be used as image material if surgery is required.

The current gold standard is the biopsy [49]. It gives a very precise measure of the exact depth even though the tissue slides are evaluated subjectively. There are however several large problems with biopsies [49]. First, a piece of skin must be removed before it is known if the burn is going to heal spontaneously or not. This will cause a scar to some degree. There is also a risk for sampling error, and if several biopsies are acquired, the scars from the biopsies will likely be worse than the scar from the burn. There is also a time aspect, as it takes quite some time before the histological preparation of a biopsy is complete. Even though biopsy is regarded as the current gold standard, the method has several drawbacks and cannot be used in clinical practice. Its role is currently isolated to animal studies because of this.

For this reason, several other methods have been suggested of which perfusion imaging techniques have received the most attention, as they have proven to be the most successful [31, 34, 35, 38, 46-50]. The two most prominent methods for perfusion measurements are laser Doppler imaging (LDI) and laser speckle contrast imaging (LSCI). LSCI is the subject of this thesis. Several other techniques have also been used such as thermal imaging, harmonic ultrasound imaging and even fluorescence for perfusion fluorometry $[31,35,49,50]$.

Thermal imaging was one of the early methods [49]. This was based on the reasoning that there should be a temperature difference between deep and superficial partial-thickness burns [31, 49]. The deep burns are generally colder than the wellperfused superficial ones $[31,49]$. This method has an acceptable accuracy, but the 
well-calibrated thermal cameras are quite expensive which has made it hard to develop systems for burn depth assessment based on thermal imaging. Nonetheless the method has seen use in several studies and reported an accuracy of up to $90 \%$, which is better than a clinical assessment $[31,49]$.

More recently there has also been some research on harmonic ultrasound imaging as a method to evaluate capillary blood flow [51]. Even though the technique is interesting and might be helpful in some situations, it still has issues with a very limited field of view and risk for sampling error [51]. It also requires contact with the injured area and pressure must be applied for optimal image quality. Ultrasound as a technique might also be more user dependent than other imaging techniques and may therefore experience a larger interobserver variation.

Fluorescence methods have been suggested and previously used for burns $[31,35$, 49]. For obvious reasons fluorescence is not very attractive as a method compared to the other methods since it requires intravenous contrast agents. Kidney failure is quite common among burn victims, with a reported incidence as high as $30 \%$ and an associated mortality of up to $80 \%$ [52]. To be dependent on contrast-reliant diagnostic measures is therefore not optimal, even if the diagnostic results are accurate.

\section{Perfusion measurement}

After several methods had been tried over the years, it was soon realized that blood flow is a suitable physical quality to examine if burn depth is to be evaluated [31, 34, $35,38,46-50]$. The logic behind this is quite simple; if there is no blood flow, there will soon be necrosis and no healing.

The basis for the current perfusion measurements are laser-based techniques [31, $34,35,38,46-50]$. The first method used for indirect perfusion measurement, in the early 1980s, was laser Doppler flowmetry (LDF), which uses the Doppler effect to estimate the velocity of erythrocytes in the tissue $[46,49,50]$. Much of this work was done at Linköping University by researchers at the Department of Biomedical Engineering (IMT). This generates a non-SI unit, which describes perfusion in arbitrary units (AU) or perfusion units (PU) [46, 50]. Consistency is guaranteed by calibrating the device. Generally, a near infrared wavelength is used as this have better properties for skin penetration and is also more specific for erythrocytes than other moving components such as proteins and water [53]. LDF only measures in a small area of $1 \times 1 \mathrm{~mm}$ and it also needs to have direct contact with the skin [53]. This makes the method prone to sampling errors. 
In the 1990s there was a new method called laser Doppler imaging (LDI), which is based on the same principle, but instead uses a laser that travels $20-100 \mathrm{~cm}$ through air, hits the intended measurement area, and the Doppler effect of the reflection is measured [31, 34, 35, 38, 46-50]. The laser then moves in a raster pattern which makes it possible to measure perfusion in a pixel per pixel fashion. The perfusion in each pixel is then converted to a color scale. The result is a perfusion image of the burn wound and surrounding uninjured skin which makes it easy for the observer to gauge the rough level of perfusion in different areas. The largest drawback with LDI is the measurement duration. Early LDI-system would require several minutes to make a perfusion image of a burn of 5-10\% TBSA [39]. During these minutes, the wounds need to be completely exposed and the patient must be perfectly still to avoid motion artefacts. Many LDI-systems also uses a class 2 laser which requires protective eyewear to minimize the risk for eye damage in the patient and clinical staff.

Early studies using LDI showed promising results and reported an accuracy of $>90 \%$ for early assessment of partial-thickness burns [33, 36, 39-41, 44, 46, 50]. Due to the aforementioned issues with motion artefacts and scan time, the technique saw limited use. With the introduction of the LDI line scanner, in the early 2000s, the scan time was reduced to 4-12 seconds depending on the size of the burn [39], which made the technique a lot easier to use. Recently some burn centers have started to use LDI for clinical assessment of burns and used this advantage to perform early surgery.

\section{Laser speckle contrast imaging}

During recent years the new method laser speckle contrast imaging (LSCI) has been developed, which is the subject of this thesis. This method uses a slightly different method than the Doppler effect to measure perfusion in a tissue. A divergent laser is used to make sure the laser is spread out over a large area, typically $20 \times 20 \mathrm{~cm}$ when images are taken from a $30 \mathrm{~cm}$ distance [46-48]. Since laser light is used, there will always be an interference pattern (see figure 4). This pattern arises because of constructive and destructive interference due to the wave-like properties of light [4648]. This interference pattern does not change over time when displayed on a flat inanimate surface like a wall for example. The phenomenon can be observed with the naked eye if a laser pointer is used. When the laser illuminates the skin, much of the light will not be reflected at the skin-air barrier, but rather from far further in. The reflection will not come from the superficial static parts of the skin, but primarily from 
the main chromophore at the selected wavelength $(785 \mathrm{~nm})$, which is hemoglobin in the erythrocytes. From a two-dimensional perspective, the illuminated area will constantly be shifting. This phenomenon can be observed by moving the laser pointer towards your own digits, the previously steady pattern from the wall will now appear blurry and shifting. A schematic example of this is shown in figures 5 and 6 .

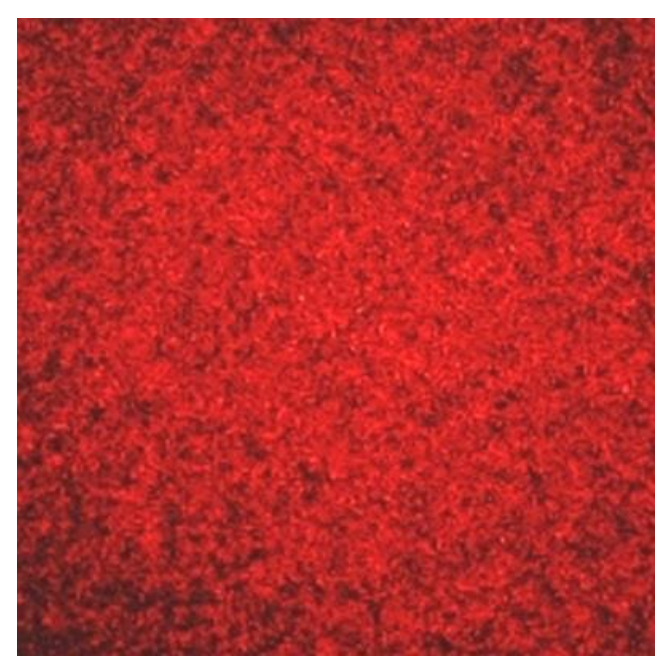

Figure 4. An objective speckle pattern originating from a red marker laser. This pattern arises because of light's wavelike properties. Some waves will coincide and cause constructive interference forming an intense spot of light. Other waves will cause destructive interference and a dark spot. This type of speckle pattern is the basis of laser speckle contrast imaging (LSCI). 


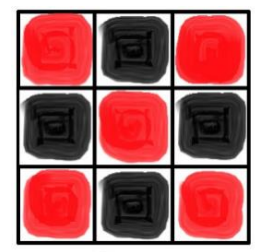

$0 \mathrm{~ms}$

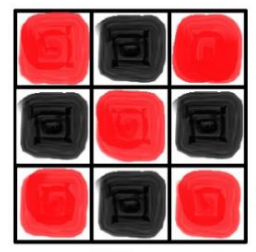

Average

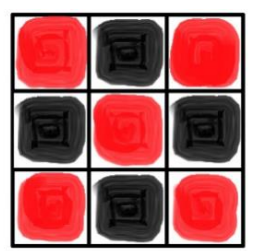

$2.5 \mathrm{~ms}$

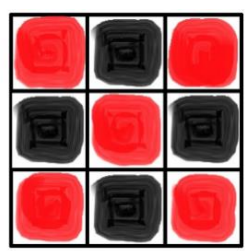

$5 \mathrm{~ms}$

- No movement

- High contrast

- Low perfusion

Figure 5. Shows a schematic view of a $3 \times 3$-pixel field. In theory, some pixels should have an intense light level (red) while other pixels have a low light level (black). A typical exposure time for laser speckle contrast systems (LSCI) is $5 \mathrm{~ms}$. The top image to the left shows the light conditions when the image recording is started, $2.5 \mathrm{~ms}$ in the middle of it, and $5 \mathrm{~ms}$ at the end. At the bottom, the final average image is seen, which is used to make perfusion calculations. If there is no movement, there is high contrast in the average image, and it is interpreted as low perfusion. Think of a sharp image captured with steady hands and no movement artefacts.

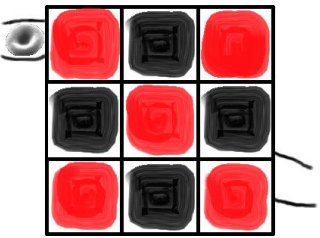

$0 \mathrm{~ms}$

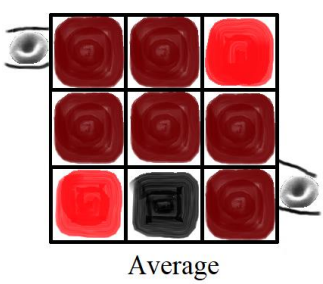

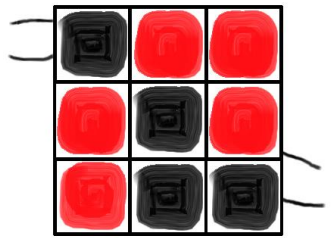

$2.5 \mathrm{~ms}$

- Movement

- Low contrast

- High perfusion

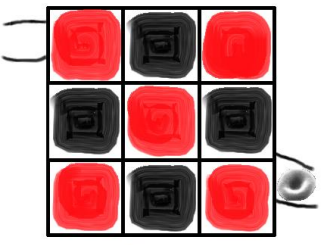

$5 \mathrm{~ms}$

Figure 6. Shows a schematic view of a $3 \times 3$-pixel field, please see Figure 5 for further explanation. At the top, an RBC is about to pass through the measurement area. At $2.5 \mathrm{~ms}$ the $\mathrm{RBC}$ has caused a substantial shift in the reflected light. When the RBC has passed through, the original light conditions are restored. As a result, the final average image has been substantially blurred (dark red). This causes a low contrast which translates to a high perfusion. This is analogous to the impossibility of getting a sharp image of a fast-moving object without drastically reducing the exposure time. 
There will also be a small contribution from other moving objects in the tissue and this remaining positive PU-signal is generally referred to as biological zero [54]. When measuring the perfusion of burns with LSCI, the biological zero is of little importance as perfusion values are generally quite high. This makes the biological zero signal negligible compared to the actual perfusion signal.

This shift in contrast is used by LSCI to quantify the blood flow in the measurement area [46-48]. This is done by calculating the variance in small windows over the image [46-48]. Depending on the LSCI-system, the size of the window will vary a bit and the system used in the thesis uses a window size of $3 \times 3$ pixels. The more movement there is in the measurement area, the lower the variance will be in the corresponding window. This is because of the shifting during the exposure time of the image. Think of a moving car and how an image of it will become blurrier with increased exposure time. If there is no movement in the tissue however, the contrast will be near perfect and the tiny dotted pattern will be discernable resulting in a high variance in the small windows.

Similar to LDI, LSCI will produce arbitrary units which are also called perfusion units (PU) [46]. These units are then converted through a scale to a color-coded perfusion image which is easy for the observer to interpret. Consistency in measurement results is guaranteed by using a calibration box with polystyrene spheres of known concentration and temperature [46-48]. Brownian motion of the spheres results in a measurable perfusion signal which is used for the calibration [46-48].

In many ways, LDI and LSCI are quite similar, there are however a few major differences. LDI always uses a scanning fashion which means that the perfusion image will be constructed of many perfusion measurements from slightly different time points. This is generally regarded to be of no consequence, but we will return to this subject at the start of the discussion section and show how this might be of great importance. LSCI captures the entire perfusion image at the same time which makes it possible to study temporal variations in blood flow over a large area. This also means that we can get a completely different image acquisition time. LSCI can capture 21 images $/ \mathrm{s}$ in an area of $20 \times 20 \mathrm{~cm}$. If this is compared to LDI, LSCI can create a perfusion image 84 times quicker. This makes LSCI much less sensitive to motion artefacts. LSCI also has better resolution, $100 \mu \mathrm{m} /$ pixel compared to $200 \mu \mathrm{m} /$ pixel of a typical LDI-system. The LSCI system also uses a class 1 laser which requires no protective eyewear. Even if the LSCI-system has many advantages over LDI, it must be mentioned that LDI measures slightly deeper into the skin than LSCI [55].

An example of a perfusion image captured with LSCI can be seen in figure 7 . 

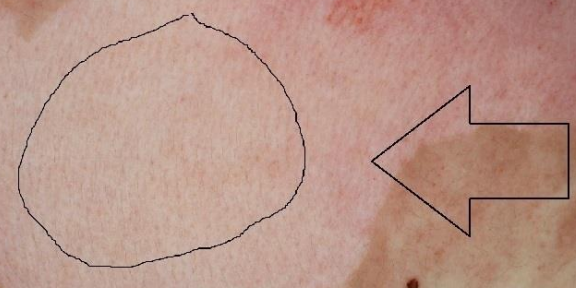

a

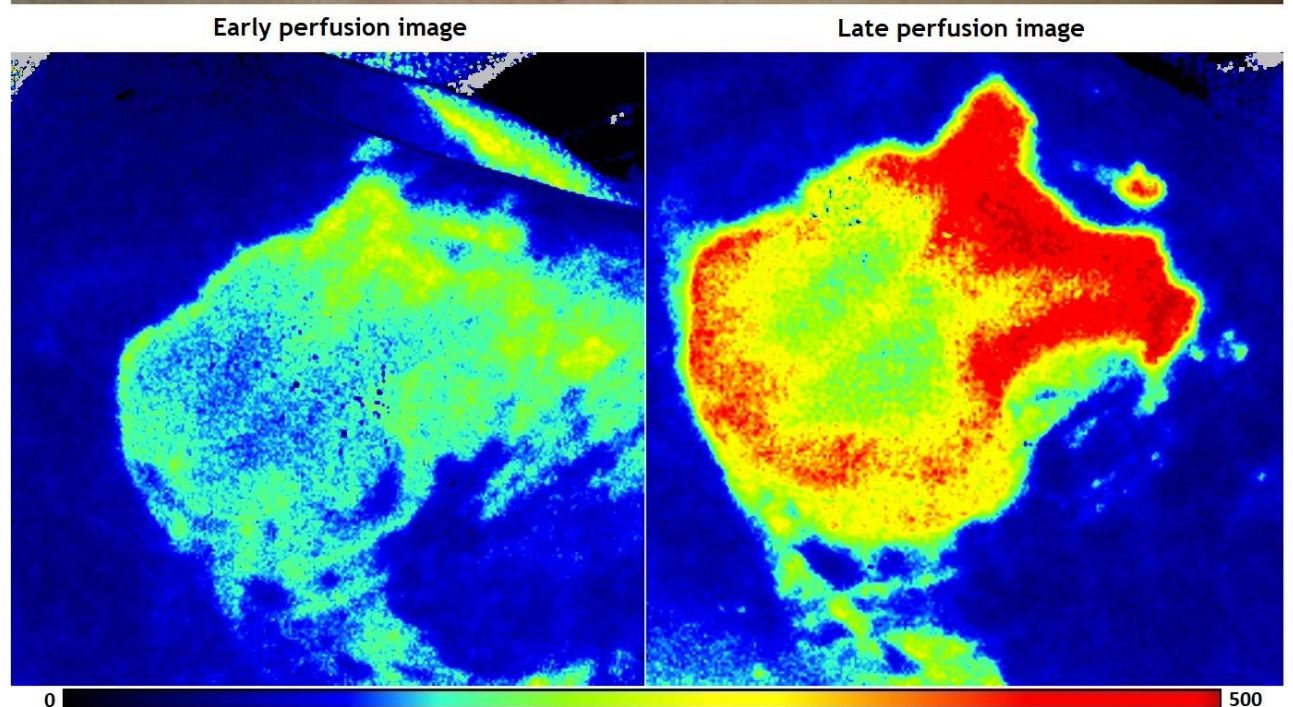

Figure 7. Perfusion images and a cross-polarized image of a scald burn. The early perfusion image was captured 17 hours after injury and the late perfusion image 4 days after injury. The crosspolarized image was captured at the same time as the early perfusion image. Notice how perfusion changes with time.

The central area in the wound with lower perfusion (greenish area) was of intermediate partialthickness while surrounding areas were of superficial partial-thickness. The central area of the wound healed within 14 days. 
Currently LDI has been studied extensively over the years and there are plenty of studies investigating LDI in human patients [33, 36, 39-41, 44, 46, 50]. In many ways, LDI is a well-established technique for burn assessment. Already day 2-5 after the injury it is possible to achieve $>90 \%$ accuracy with both LDI and LSCI when evaluating surgical need [33, 36, 39-41, 44, 46, 50, 56, 57]. The primary reasons for the low usage are likely the cumbersomeness of the equipment, problems with motion artefacts, problems with evaluating the images, and cost aspects.

LSCI as a technique is a lot more recent and has so far only been used in a few studies with human patients [56-61]. During the last 5 years, LSCI has however received increasing attention and is now being used more and more within different areas. So far, LSCI has seen little use in human burn research [61]. Most studies using LSCI have so far been animal studies, and most studies in human patients ever published are contained within this thesis. There are however several aspects of LSCI which are still being developed. One of the most promising aspects is the multiexposure LSCI which uses different exposure times to draw further conclusions about the analyzed tissue [61].

Another aspect of LSCI that has so far received little attention is the ability to use the camera to record perfusion over time in large areas. During normal physiological conditions there are substantial fluctuations in blood flow to the microcirculation. These fluctuations are primarily caused by contraction and relaxation of small resistance vessels, and by cardiac activity [62-64]. This phenomenon is generally referred to as vasomotion and the measured signal is often referred to as flowmetry [65]. This is an interesting area of research where most of the research to date has been done with LDF.

To summarize, current perfusion research is promising and has provided us with several methods for determining surgical need in burn wounds; but actual wound depth cannot be determined until at least 2 days have passed after injury [33, 56]. It would therefore be of great interest to find reliable methods that work within the first 48 hours after injury. 


\section{Vasomotion}

The microcirculation consists of the smallest order of blood vessels, with a diameter of $<150 \mu \mathrm{m}[66,67]$. On this circulatory level, oxygen and nutrients are exchanged between the blood and the tissue [66,67]. A functioning microcirculation is essential to any organism and the microcirculation has therefore been of great interest to better understand many physiological and pathophysiological conditions. Vasomotion has received a lot of attention and is generally described as organized and chaotic fluctuations of the vessel diameter primarily occurring in the microvasculature over time [63, 64]. The concept of vasomotion was first described in 1852, but it is still in many ways a mysterious concept where the actual physiological gain is poorly understood [68]. Vasomotion is assumed to improve the flow to the target tissue and it is often inducible by creating stressing situations for the tissue $[63,64]$.

The mechanisms behind vasomotion have been studied quite thoroughly. It is currently believed that the desynchronized vasomotion arises at a cellular level in arterioles and then propagates through intercellular gap junctions to affect the entire vessel and sometimes even adjacent vessels [63, 64]. Calcium channels and nitric oxide has proved to have important mediatory functions for vasomotion. By using these pathways, vasomotion can both be induced and inhibited [63, 64].

If the frequency spectra of perfusion change over time is analyzed, it is possible to divide vasomotion into different frequency bands $[63,64]$. Each such frequency band is also associated with a specific origin of the vasomotion activity [63, 64]. The currently established frequency bands are as follows: cardiac activity $(0.6-1.6 \mathrm{~Hz})$, respiratory activity $(0.15-0.4 \mathrm{~Hz})$, myogenic activity $(0.06-0.15 \mathrm{~Hz})$, neurogenic activity $(0.02-0.06 \mathrm{~Hz})$, and endothelial activity $(0.0095-0.02 \mathrm{~Hz})$ [69]. These different bands have been established by abolishing certain pathways upon which the specific frequency band disappears.

Besides these previously described frequency bands there are two additional phenomena which cause changes in perfusion over time. The first phenomenon is called Mayer waves, which appear because of a lagging effect in baroreceptors [63, 64]. This causes an oscillatory effect on perfusion in humans of $0.1 \mathrm{~Hz}[63,64]$. This corresponds roughly to the same frequency band as myogenic activity. The second phenomenon, called perfusion dips, consists of synchronized bursts of vasoconstriction in glabrous skin which is suspected to be mediated through sympathetic innervation [70]. Perfusion dips likely have a heat regulatory function and therefore has a high degree of variation in their frequency.

There is also a large difference between the different types of vasomotion activity which is important to understand. Some of these frequency bands arise from chaotic 
fluctuations and is therefore highly local in their nature [63, 64]. For example, endothelial vasomotion activity is highly chaotic and will not show synchronized changes if many vessels are investigated simultaneously. In a similar way, neurogenic activity and myogenic activity are also chaotic and not synchronized over large areas $[63,64]$. Aspects such as respiratory and cardiac vasomotion activity will however be synchronized in the entire body since the fluctuations are driven by central mechanisms. The same holds true for Meyer waves and perfusion dips which are also centrally mediated. This has one important implication, LDF-application are better at studying the desynchronized parts of vasomotion while LSCI is required to study synchronized vasomotion over large areas. LSCI can be used to study the desynchronized parts of vasomotion too if zooming optical equipment is used [71].

\section{Cardiac vasomotion activity}

Different aspects of the cardiac vasomotion are already used daily in modern healthcare. Standard medical equipment such as pulse oximetry provides information about pulse and perfusion index by this method. When the different aspects of vasomotion are investigated in more detail, it is quickly realized that cardiac vasomotion activity is the major drive behind the large observable perfusion fluctuations. This is easily seen in the middle graph of figure 8 where cardiac vasomotion was not removed. Cardiac activity also has the benefit that it has the highest frequency which makes it easier to study, as the required measurement time is short.

If we want to use vasomotion as a diagnostic tool for burns, cardiac vasomotion would be suitable. It is synchronized in the entire burn and in the surrounding uninjured skin. It is easy to measure with perfusion scanning equipment since the variation in perfusion is substantial. Most patients also have a sufficiently high pulse rate that a measurement time of 4-8 seconds provides enough information. It is however important to remember that only LSCI can be used for this since the entire image must be captured at the same time. 
Particularly scalds have been shown to undergo a process called burn wound conversion [72-74]. Many burns will often appear as superficial partial-thickness the same day as the injury occurred [72-74]. Over time several processes occur however and at around 48 hours many wounds will have converted into a deep partial-thickness wound $[73,74]$. So far, there have been many suggestions regarding pathophysiological mechanisms responsible for these changes. The current hypotheses are based around microcirculatory dysfunction and that it makes the vasculature more susceptible to microthrombosis which further exacerbates the microvascular damage [72-74]. These findings are based on animal studies and for several reasons it is very hard to perform these studies in humans since they require prepared areas where it is possible to continuously observe the microcirculation under microscope.

If we assume these findings hold true for humans too, a scald that is at least a few hours old should be in an accelerating state of vasoconstriction and microthrombotization which should cause two things in the damaged skin: a reduction of perfusion and a reduction of the cardiogenic vasomotion, since there are fewer patent arterioles for the heartbeat to propagate through. Scalded areas which will not undergo burn wound conversion would on the other hand still have patent vessels and show normal cardiogenic vasomotion. This means that vasomotion might be a valuable tool in early burn wound diagnostics.

\section{Pulsatility}

Since cardiac vasomotion is not the only deciding factor for early burn diagnostics, the actual perfusion must also be considered, which has been shown to be a reliable indicator of burn depth. This is the basis of paper IV of this thesis, where cardiac vasomotion and perfusion were combined into a measure of "pulsatility". In this thesis it is shown that this provides a new method for determining surgical need in burns to be used the same day as the injury occurred. 

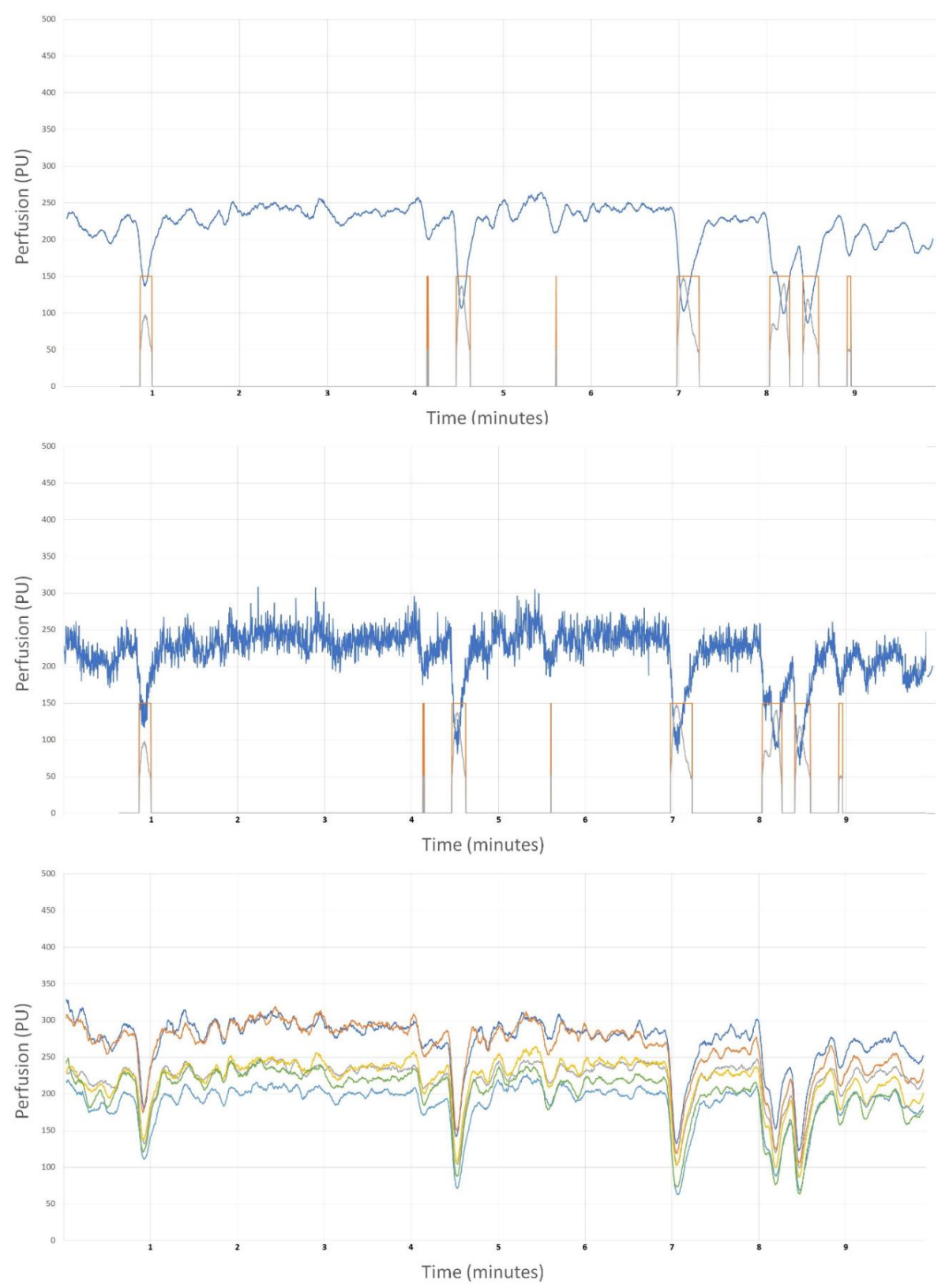

Figure 8. Perfusion signal from the nail bed in a resting state. Perfusion as PU is shown on the yaxis and time in minutes on the $\mathrm{x}$-axis. The dark blue line in the top graph shows the $4 \mathrm{~s}$ moving average of the perfusion signal from dig II sin. The dark blue line in the middle graph shows the raw perfusion signal from dig II $\mathrm{dx}$. The orange lines and the grey lines in the top and middle graph show detected perfusion dips and area under the curve (AUC), respectively. The bottom graph shows the $4 \mathrm{~s}$ moving average of the perfusion signal from each digit with: dark blue $=$ dig II $d x$, orange $=\operatorname{dig}$ II $\sin$, green $=\operatorname{dig}$ III dx, yellow $=\operatorname{dig}$ III $\sin$, light blue $=\operatorname{dig}$ IV dx, and green $=\operatorname{dig} \mathrm{IV} \sin$. 


\section{Aims of the thesis}

The goal of this thesis was to investigate how LSCI could be used as a diagnostic tool for burn depth assessment. When the work started in 2015, few studies of LSCI usage in burns existed. For this reason, the majority of current LSCI burn research carried out in a human material is contained within this thesis. It therefore felt necessary to include a comprehensive guide to LSCI measurements in burns, as no such summary has been published.

Specific aims for the included studies in the thesis:

1. The aim of the first study was to investigate perfusion trends in scalds and to establish optimal time windows for diagnostic measurements. We hypothesized that the perfusion would vary significantly from day to day during the first week after injury.

2. The second study's primary goal was to establish cut-offs for perfusion values that could predict the need for surgical intervention. We hypothesized that a double measurement method would achieve higher accuracy.

3. In the third study, interobserver variability was investigated. If LSCI is used in the clinic, it is essential to understand how surgeons use perfusion images. It is also important to evaluate how inexperienced LSCI-users would use the images. We hypothesized that perfusion values would not differ between observer groups. We also hypothesized that burn experience would improve the accuracy of assessments.

4. In the last study, we wanted to investigate if cardiac vasomotion could be used for early burn diagnostics. The primary aim was to evaluate the early accuracy of this method and its reproducibility. We hypothesized that the optimal measurement duration would be between 1 and $12 \mathrm{~s}$. We also hypothesized that pulsatility could reliably predict surgical need on the day of injury. 


\section{Methods}

\section{Subjects}

All patients were recruited at the Department of Plastic Surgery, Hand Surgery and Burns at Linköping University Hospital, Sweden. A total of 77 patients were included in the thesis. The patient material in paper IV was unique from paper I and paper II. All patients included in paper I were also included in paper II. Before inclusion, all patients or their legal guardian gave oral and written informed consent. The perfusion measurements were done in conjunction with change of wound dressings. Dressing frequency was not changed on account of the study and the healing process was monitored at each subsequent dressing. During the later stages of wound healing, additional clinical information was sometimes attained from responsible nurse or from journal entries of the responsible doctor. In most cases, normal digital images were also captured during routine dressing change. This made it possible to double check all information and to accurately establish the healing time. All research was approved by the regional ethics review board, DNr 2012/31/31.

\section{Equipment}

A laser speckle contrast imager (PeriCam PSI System, Perimed AB, Järfälla, Sweden) was used to measure perfusion. A description of LSCI can be found in the introduction section on page 13. This system has previously been described in detail [58] and potential sources of error during routine measurement have also been investigated [75].

LSCI uses a divergent laser to create a speckle pattern in the measured tissue. The changes in this speckle pattern are then used to quantify the perfusion into arbitrary perfusion units (PU). All PU-values are then converted into a color-coded image.

Slightly different measurement setups were used for the different papers. The measurement distance was always kept between 25 and $35 \mathrm{~cm}$. The recording rate was also kept the same in all papers at a rate of 21 images/s. In paper I and paper II, images were averaged 42:1 which made the recording time 2 s. In paper IV, LSCI-video recording was used with an averaging of 4:1 giving a final frequency of $5.25 \mathrm{~Hz}$. In paper I and paper II, the image size was set to correspond to $12 \times 12 \mathrm{~cm}$ while this was set to $18 \times 18 \mathrm{~cm}$ in paper IV after acquisition of an updated LSCI-system, but otherwise of the same model and make. 
In paper III normal RGB-images were also used and these were captured with a digital camera (Canon Eos 600D, Canon Inc., Tokyo, Japan). This camera was also equipped with a cross polarization system. This removes specular reflections from fluids in the wounds, which greatly improves image quality in most cases. The RGBimages were captured from a distance of roughly 18 to $27 \mathrm{~cm}$.

\section{Clinical setting}

All LSCI measurements were made by the author, except for a few of the early measurements included in paper I and paper II. Most measurements were done day 0-5 after injury. In paper I, all patients were followed until at least 14 days after injury and a formal surgery decision was made.

All patients included in the measurements received some form of sedation and the method of sedation was selected at the discretion of the responsible anesthesiologist. The most commonly used anesthesia was a combination of midazolam and ketamine/esketamine. A few images were also captured in patients under general anesthesia, were propofol was the drug of choice.

The most commonly used dressing material was Mepilex Ag (Mölnlycke, Health Care AB, Gothenburg, Sweden). When more superficial partial-thickness wounds were near closure, Mepilex (Mölnlycke, Health Care AB, Gothenburg, Sweden) was sometimes used at the discretion of the responsible nurse. In some patients, a porcine xenograft (EZ Derm, Mölnlycke, Health Care AB, Gothenburg, Sweden) was used. Since these xenografts interfere with perfusion measurements, this often prevented follow up measurements.

\section{Perfusion measurements}

In paper I and paper II, perfusion image material was collected of the burns in their entirety. All analysis of the material was done after image collection.

In paper IV, perfusion images were collected in a slightly different manner. First a quick perfusion scout scan was made to reveal areas of low perfusion, which often generated 0-4 areas of interest. This was combined with a clinical examination to find areas difficult to evaluate clinically. When all areas of interested had been identified, a 
prolonged measurement was done in the areas of interest and each of these measurements had a duration of 30-60s.

Afterwards, regions of interest (ROI) were created in areas of interest to create a fair representation of the different perfusion areas present in the wound. If a ROI was situated in an area with low perfusion, the area had to have a diameter of $>2 \mathrm{~cm}$ to qualify for surgery. If the area was smaller, it was considered too small for any procedure and was not included in calculations. The reason for this, is the proximity of nearby viable tissue, which helps to expedite the healing of these wounds anyway. This makes surgery redundant when the wound is small.

A comprehensive guide with reasoning behind ROI-creation is included as an appendix to this thesis. No ROI-guide has previously been published and it aims to convey how marking was done in the different papers of the thesis. It also contains some anecdotal examples of specific patterns and common pitfalls to avoid.

\section{Interobserver trial}

There were three different observer groups in paper III. None of the observers had any previous experience with LSCI. The first group consisted of four plastic surgeons working with burns, the second group of registered nurses working with burns, and the last group of junior doctors with little or no experience of burns. Each observer received a standardized oral presentation on the LSCI subject aided by a PowerPoint presentation. They were also thoroughly informed about their task in the same presentation. Additionally, each observer received a short LSCI pamphlet which they could consult during the trial. The observers could ask any questions during the presentation but not during the trial itself. The only question they could ask during the trial was whether a certain area was an optical artefact or not. Each such question was always answered with a yes or no response.

The task consisted of assessing 20 perfusion images from 10 patients, this material consisted of images collected for paper IV. One perfusion image was captured 0-24 hours after injury (early image) and the second, 72-96 hours after injury (late image). The observers also had access to 10 normal RGB-photos of the same injuries from either the early or the late measurement. Each RGB-photo had a pre-marked area which marked the area of interest. After the observer had marked both the early and the late perfusion image, they put the perfusion values into a prepared formula in an Excel-sheet. This generated a recommendation based on the formula presented in paper II. The observer was informed to use their clinical experience and disregard the recommendation if they did not believe it to be true. Observers then selected between 
four different categories: "spontaneous healing / 0", "maybe spontaneous healing / 0.33 ", "maybe surgery / 0.67 ", and "surgery / 1".

The 10 cases consisted of nine scalds and one contact burn. Three of these cases went through excision and split-thickness skin grafting after the wound failed to heal after 14 days. One of the cases consisted of a small ROI of $1 \times 2 \mathrm{~cm}$ which required 21 days to fully heal. For this specific case "maybe spontaneous healing" was deemed the most reasonable assessment. The remaining six cases were scalds that healed in 1-2 weeks.

There was one contact burn in the study, which was one of the three cases that required surgery. Contact burns generate somewhat anomalous results when the formula in paper II is used. When the perfusion value from this case was put in in a correct manner, it would generate a false recommendation. This was intended as a pitfall for the observers to investigate if the observers experienced in burns would be able to spot the false recommendation.

\section{Data analysis}

In paper II and IV, two different formulas were developed to predict surgical need based on the perfusion data.

The formula in paper II calculated the change in perfusion over time based on an early measurement (0-24 hours) and a late measurement (72-96 hours). There were however two concerns that had to be dealt with by the formula. First, some wounds had a high initial perfusion. If only the derivative was used, this would give false positive results in a few superficial partial-thickness wounds. Secondly, when the initial perfusion was very low, the additional decrease at the second measurement was less pronounced. This created false negative results for some deep partial-thickness wounds. 
To solve these two concerns, we added a weight for initial perfusion and a condition for initial perfusion. The final formula was the following, where $(\Delta P)$ is perfusion change over time, $p_{1}$ is early perfusion, $p_{2}$ is late perfusion, and $p_{\mu \text {, surgery }}$ the average perfusion for surgery cases:

$$
\begin{gathered}
p_{1}<p_{\mu, \text { surgery }}+3 S D \\
\Delta P_{\text {mod }}=\frac{p_{2}-p_{1}}{72}+\frac{p_{1}}{p_{\mu, \text { surgery }}}-1
\end{gathered}
$$

In paper IV we developed another formula to consider the pulsatility in the burn. This formula was based on the average change in perfusion between adjacent measurement points in time. These perfusion changes over time were assumed to be caused by cardiac vasomotion. The average perfusion value was also an important aspect when calculating the final pulsatility value, which was the product of cardiac vasomotion and average perfusion. To make the pulsatility values similar to values produced from the formula in paper II and easy to differentiate from perfusion values in general, the results were divided by a scale factor $\left(10^{3}\right)$. The final formula was the following, where $\bar{P}$ is the average perfusion in PU, $p(k)$ the perfusion value of the $k^{\text {th }}$ measurement point in $\mathrm{PU}$, and $N$ the number of measurement points:

$$
\text { Pulsatility }=\frac{\bar{P}}{10^{3}} \times \frac{1}{N} \sum_{k=2}^{N}|p(k)-p(k-1)|
$$

Statistical analysis

This is a description of the different statistical analyses that were used in the different studies of the thesis. All statistical analyses were made with the aid of GraphPad Prism version 5.02 for Windows (GraphPad Software, San Diego California USA, www.graphpad.com), SPSS version 25 (IBM, Armonk NY, USA, www.ibm.com), Excel 2013 (Microsoft, Redmond Washington USA, www.microsoft.com), Excel 2016 (Microsoft, Redmond Washington USA, www.microsoft.com), and Excel (Microsoft, Redmond Washington USA, www.microsoft.com). 
Paper I:

Perfusion values were divided into different time intervals. For wounds less than 24 hours old, the division was made into 6-hour intervals. Injuries older than 1 day where divided into 24-hour intervals. All wounds were also assigned a category depending on the observed healing time: 3-4 days, 5-7 days, 8-11 days, 12-18 days, or surgery needed.

A one-way analysis of variance (ANOVA) was used to test for differences in healing time in relation to age. Two-tailed Student's t tests with Welch's correction was used to compare the different healing time categories to each other within the time intervals: 6-12 hours, 18-24 hours, and 72-96 hours after injury. Welch's correction was used because of differences in variance between the groups.

Paper II:

The perfusion values were divided into three different timer intervals: 0-14 hours, 1524 hours, 72 hours, and 96 hours after injury. All wounds were assigned the same healing time categories as in paper I: 3-4 days, 5-7 days, 8-11 days, 12-18 days, or surgery needed. This study also investigated the accuracy for clinical assessments done in 30 of the 45 patients, generating a total of 33 ROI for comparison.

Differences in perfusion between the different time and healing time categories were analyzed using ANOVA with Sidak's correction for multiple comparisons.

Receiver operator characteristics (ROC) curves were constructed to investigate optimal cut-offs at 0-24 hours and 72-96 hours after injury. Additionally, all cases which had perfusion values at both 0-24 hours and 72-96 hours after injury were evaluated using the formula described in the data analysis section on page 29. A ROC curve was then constructed using the results from the formula. Youden index was used to establish optimal cut-offs.

The accuracy of clinical assessment was analyzed using Cohen's $\kappa$, where this was compared to perfusion data from 72-96 hours. Because the question to the surgeon was formulated as "Do you believe this wound area will heal within 14 days?" a different perfusion cut-off was used. To draw the line at 14 days must be considered suboptimal in light of the findings from paper I. Even though unconventional, Cohen's $\kappa$ was selected as a method to eliminate chance agreement, which is a large confounder in this type of study. 
Paper III:

Differences between the observers' characteristics were analyzed using a one-way ANOVA with multiple comparison using Fisher's exact test.

Perfusion values and assessments generated by the observers were analyzed using intra-class correlation (ICC). ICC was selected to eliminate chance agreement and because it allows for analysis of ordinal and ratio scales. An ICC analysis testing absolute agreement was used and ICC values were reported as single measurements.

The accuracy of the assessment done by the observers were analyzed with weighted kappa because the variable was ordinal. The weight was set to 1 for the first ordinal level with increments of 1 per level. The use of weighted kappa is rare but suitable from a mathematical point of view to investigate ordinal agreement where chance agreement must be eliminated.

Paper IV:

All perfusion values were combined with the cardiac vasomotion to form pulsatility. All measurements were made the first 5 days after injury and these measurements were divided into two groups: 0-2 days after injury (85 measurements) and 3-5 days after injury (102 measurements). Unlike paper I and paper II, each wound was assigned into two healing time groups instead of five. These were: healing within 3-20 days or healing $\geq 21$ days/surgically treated.

Reproducibility was tested for different measurement durations. This was done by comparing pulsatility values with the same measurement duration from the same recording. This generated an individual coefficient of variation (CV) and SD for each recording and measurement duration. $\mathrm{CV}$ and $\mathrm{SD}$ were then averaged for all recordings contributing to a specific measurement duration. To qualify for inclusion, the recording had to be free from motion artefacts for a duration of at least 24 seconds.

The degree of motion artefacts was evaluated by the author through manual inspection, looking for sudden spikes in the perfusion signal and blurriness in otherwise sharp parts of the image.

ROC curves were constructed for all measurements of 4 and 8 seconds. Youden index was used to establish optimal cut-offs. 


\section{Review of the studies}

\section{Paper 1}

Purpose:

The aim of this study was to describe the dynamics of perfusion in scald burns. The goal was to find the optimal time range for surgical decision making.

\section{Results:}

The perfusion values from a total of 149 ROI in 34 patients were included. The perfusion values were measured between 0 and 15 days after injury. In this study, we were able to show specific perfusion dynamics in relation to healing time.

The superficial partial-thickness burns with a healing time of 5-11 days showed an early increase of perfusion of up to 60-90\% 72-120 hours after injury from already high perfusion levels. On a group level, shorter healing time was associated with an earlier peak and earlier perfusion decrease. The perfusion over time curve therefore had a much sharper peak in these burns. The superficial burns, with a prolonged healing time of 12-14 days, had a more hill like shape to their perfusion over time curve.

Deep partial-thickness burns with a healing time $>20$ days showed an early perfusion decrease the first 48-72 hours and entered a plateau phase, which lasted a week before an increase in perfusion was observed. The average decrease was around $25 \%$ compared to initial values. After roughly 11 to 15 days, a perfusion increase occurred in these burns.

The partial-thickness burns of intermediate thickness with a healing time of 12-18 days, had a combination of properties. There was an average increase in perfusion of $20 \%$ from the first 24 hours to $72-120$ hours after injury. The increase was less pronounced compared to the superficial partial-thickness burns, but it was also slower to subside.

An example image of these different categories is shown in figure 9. 


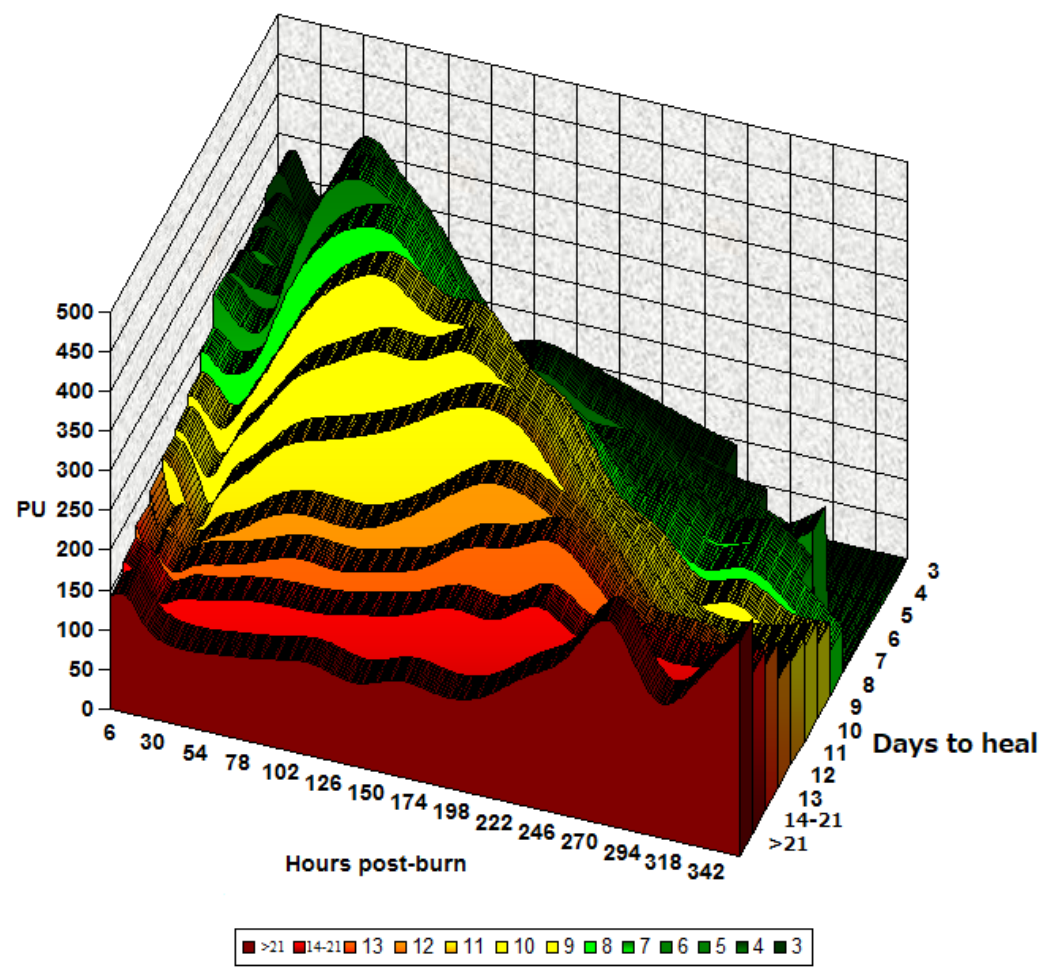

Figure 9. Shows linear interpolated and extrapolated perfusion values over time in relation to healing time. More superficial wounds are colored green while deeper wounds are colored red. Notice how the early perfusion increase is diminished with increasing healing time.

\section{Conclusions:}

With the data from this paper we could conclude that the time of measurement of the perfusion in burns is essential. We concluded that the optimal measurement window is between day 3 to 5 after injury, when the differences in perfusion was the largest between wounds of different healing times. The potential advantage with two measurements was also discussed. 


\section{Paper II}

\section{Purpose:}

The main goal of this study was to investigate the accuracy when using LSCI to predict surgical need. It was essential to investigate the precision in early measurements as well as late measurements. We also wanted to evaluate advantages with a double measurement approach.

\section{Results:}

A total of 195 ROI from 45 patients were included in this study. All data points were recorded between 0-5 days after injury. In this study, we could show that LSCI has a very high accuracy when using single measurements 72-96 hours after injury. We could also show that a double measurement improved accuracy even further.

Perfusion did not differ significantly between measurements done at 72 and 96 hours after injury. The same was true for perfusion measurements done between 0-14 and 15-24 hours after injury.

The measurements made during the first 24 hours achieved a reasonable accuracy with a sensitivity of $92.3 \%$ (95\% CI: $64.0-99.8 \%$ ) and specificity of $78.3 \%$ (95\% CI: 69.9-85.3\%) at the cut-off $173 \mathrm{PU}$. The positive predictive value (PPV) was quite poor however at $31.6 \%$, but the negative predictive value (NPV) was excellent at 98.9\%. A PPV indicates successful identification of surgical need while an NPV shows successful identification of spontaneous healing.

For the measurement time 72-96 hours after injury, we considered two potential cut-offs. The first was at 170 PU giving a sensitivity of $100 \%$ (95\% CI: 83.9-100\%) and a specificity of $90.4 \%$ (95\% CI: 83.8-94.9\%), while PPV was $63.6 \%$ and NPV $100 \%$. The second cut-off was at 130 PU with a sensitivity of $71.4 \%$ (95\% CI: 47.8 $88.7 \%$ ) and a specificity of $100 \%$ (95\% CI: $97.1-100 \%$ ), with a PPV of $100 \%$ and NPV of $95.4 \%$. This meant that wounds between 130-170 PU where in a gray area with some overlap between surgery cases and wounds healing in 12-18 days.

When the double measurement approach was used, we could improve our results. A cut-off at $-0.35 \mathrm{mod}$ PU/hour resulted in a sensitivity of $100 \%$ (95\% CI: $59.0-100 \%$ ) and a specificity of $100 \%$ (95\% CI: $95.1-100 \%$ ), and thus a PPV and NPV of $100 \%$.

The following formula was used, where $(\Delta P)$ is perfusion change over time, $p_{1}$ is

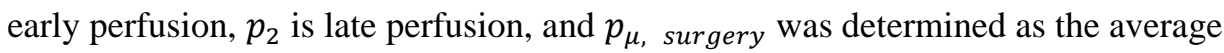


perfusion for surgery cases. The standard deviation (SD) of the material was used to determine an upper perfusion limit for when the formula should be used. Assuming a Gaussian distribution, only $0.1 \%$ of surgery cases would mistakenly be excluded by this upper limit if it was set to 3 standard deviations:

$$
\begin{gathered}
p_{1}<p_{\mu, \text { surgery }}+3 S D \\
\Delta P_{\text {mod }}=\frac{p_{2}-p_{1}}{72}+\frac{p_{1}}{p_{\mu, \text { surgery }}}-1
\end{gathered}
$$

\section{Conclusions:}

In this study we could conclude that LSCI has a high accuracy to predict surgical need 3-4 days after injury. There was no significant difference whether the measurement was done day 3 or day 4 . We were also able to show that perfusion did not change significantly within the first 24 hours after injury. Finally, we could show that a double measurement improves accuracy. This led to the creation of a potential flow chart (see figure 10), which was not published in the original paper. 


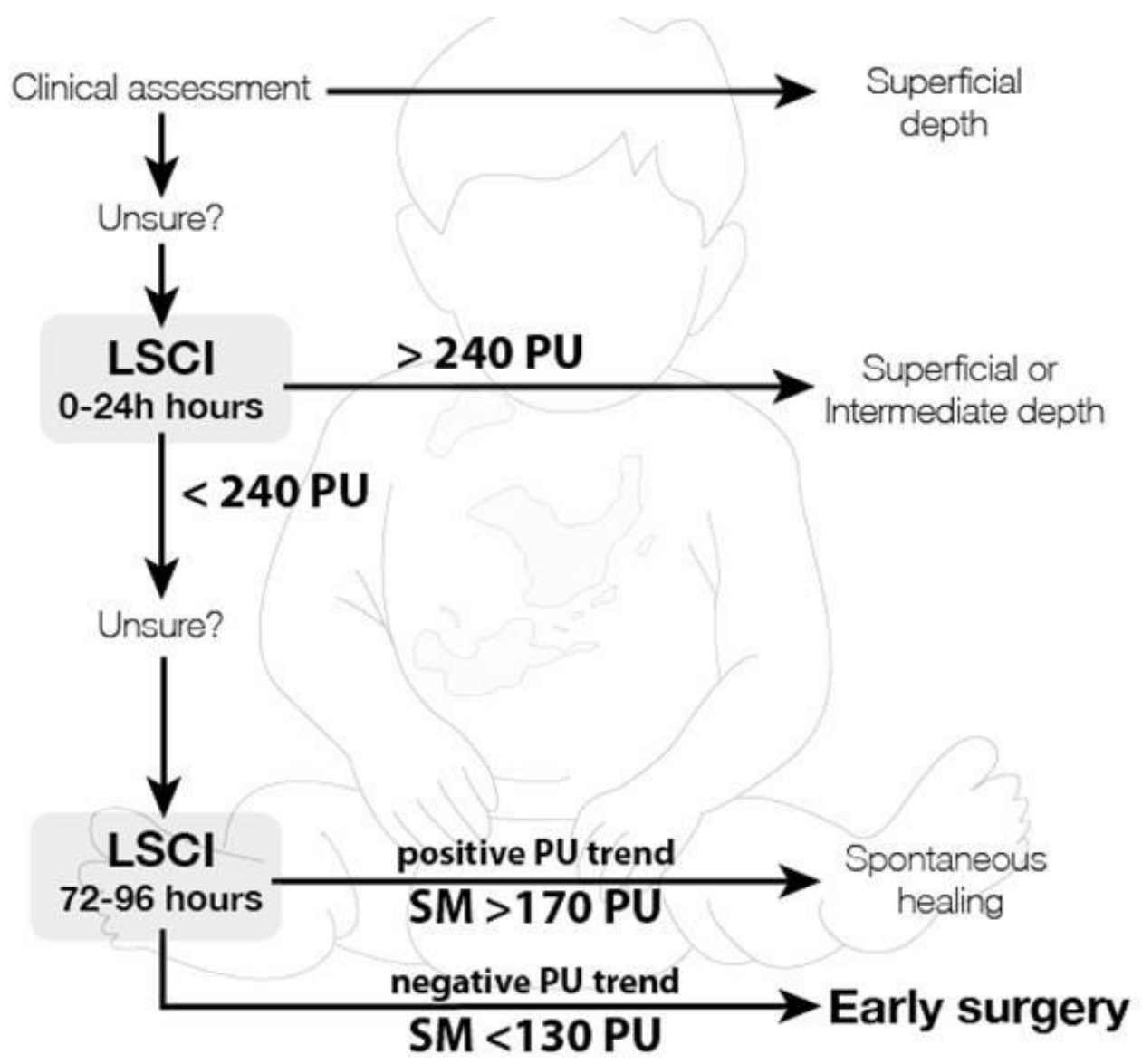

Figure 10. Flowchart based on the findings in paper II. A sound clinical assessment should be done before perfusion measurements. If there is any suspicion of deeper wound areas, a perfusion measurement should be the next step. If the initial scan shows a perfusion $>240$ perfusion units (PU), spontaneous healing should occur. If the perfusion is lower than $240 \mathrm{PU}$, a repeat measurement should be done day 3-4 after injury. If $\Delta P_{\text {mod }}$ is <-0.35, surgery must be considered. If initial presentation of the patient occurs 3-4 days after injury, a single measurement (SM) with a perfusion $>170$ PU can be used to rule out surgical need. A SM <130 PU day 3-4 strongly suggest surgical need, however. 
Paper III

Purpose:

In this study, we investigated how inexperienced LSCI-observers would use perfusion images. Differences between profession groups and the benefits of burn experience was also investigated.

Results:

There was a total of 12 observers evenly recruited from the three different profession groups. Each observer created a total of $20 \mathrm{ROI}$ in 20 perfusion images from 10 patients.

The perfusion from the marked ROI had very similar values and a pooled ICC of all groups had an agreement of 0.98 (95\% CI: 0.95-0.99) in the early perfusion images, 0.95 (95\% CI: 0.90-0.99) in the late perfusion images, and 0.94 (95\% CI: 0.87-0.98) when $\Delta P_{\text {mod }}$ from paper II was used. Agreement of perfusion values can be seen in figure 11 .

On the contrary, the agreement of burn depth assessments was quite poor. ICC was used to calculate agreement of assessments. Among plastic surgeons the agreement was 0.30 (95\% CI: 0.04-0.67), in the nurse group it was 0.51 (95\% CI: 0.21-0.81), and in the junior doctor group it was 0.75 (95\% CI: 0.50-0.92). Agreement of assessments can be seen in figure 12 . 

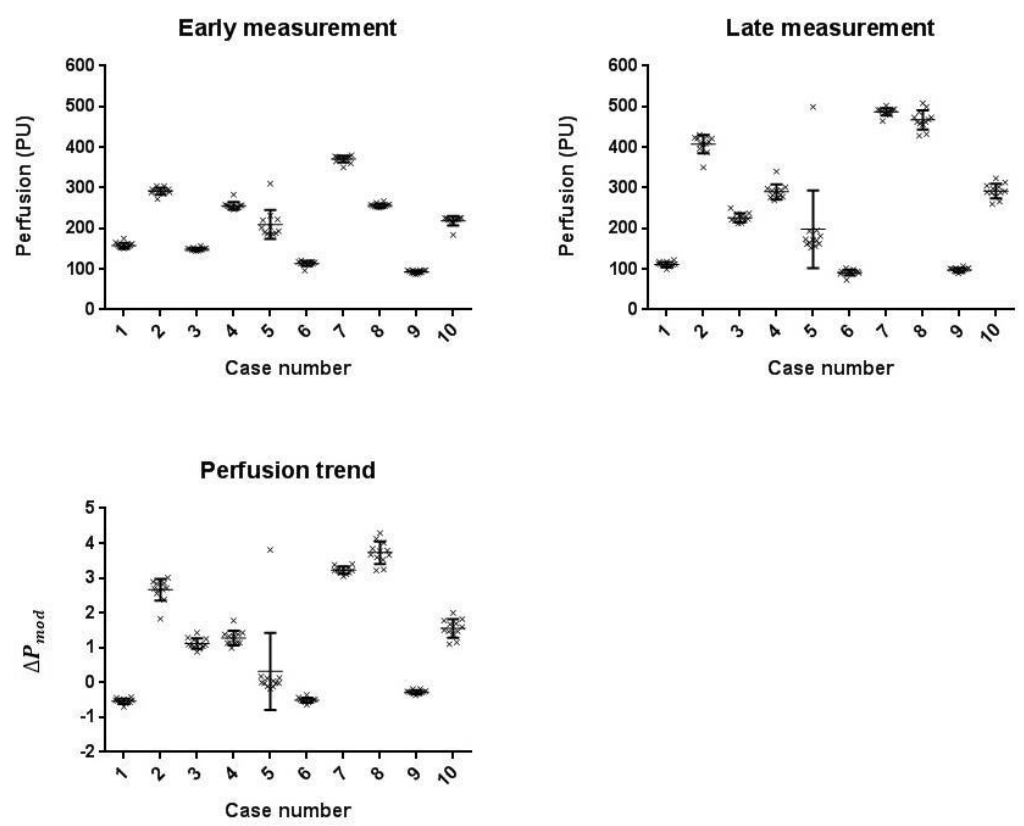

Figure 11. Scatterplots of each observers' recorded perfusion values and perfusion trend values. Horizontal bars show the average value and vertical error bars the standard deviation. Case number can be seen on the $\mathrm{x}$-axis and the $\mathrm{y}$-axis measures either perfusion or perfusion change $\left(\Delta P_{\text {mod }}\right)$. Perfusion change was obtained by using perfusion values from both the early and the late measurement.

Burn depth assessment

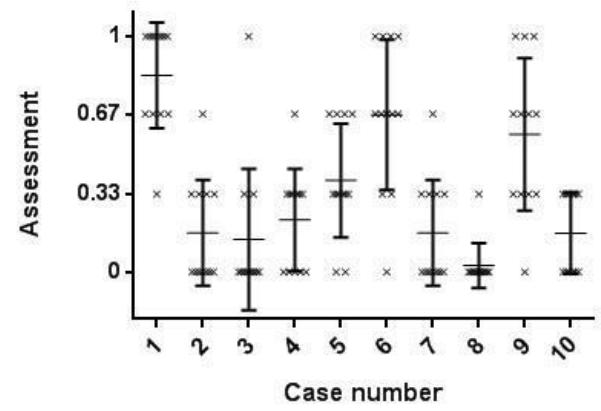

LSCI recommendation

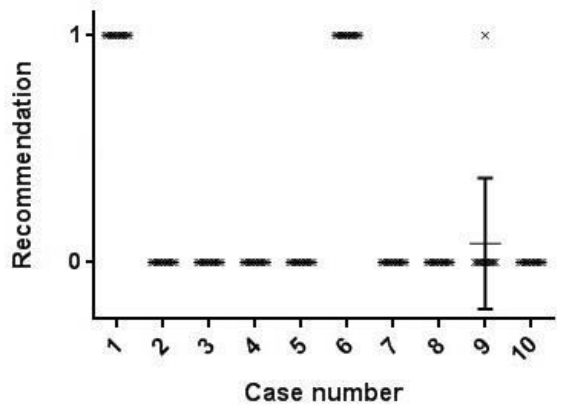

Figure 12. Scatterplots of each observers' assessment and the LSCI-recommendations they received. Horizontal bars describe the average value, whereas vertical error bars show standard deviation. Case numbers are shown on the $\mathrm{x}$-axis. On the $\mathrm{y}$-axis, the assessment done by each observer can be seen and the LSCI-recommendation they received.

$0=$ 'spontaneous healing', $0.33=$ 'maybe spontaneous healing', $0.67=$ 'maybe surgery', $1=$ 'surgery'. 
The accuracy of the assessments was also compared to the true outcome, which was calculated using weighted kappa. The kappa value was 0.38 in the plastic surgeon group, 0.62 in the nurse group, and 0.60 in the junior doctor group.

The accuracy of the LSCI recommendations was 0.74 for the plastic surgeons, 0.74 for the nurses, and 0.80 for the junior doctors. The agreement of LSCI recommendations can be seen in figure 12. Case number 9 was included to trick the observer, since this contact burn generated a false recommendation. 7 out of 12 observers selected surgery for this case but burn experience did not seem advantageous in identifying this case. 3 out of 4 junior doctors believed that surgery would be needed, while 3 out of 4 of the nurses selected surgery, but only 1 out of 4 plastic surgeons.

To make sure that case 9 would not confound the results, we also analyzed all results without this case included. This did not cause any large changes except for the accuracy of the LSCI recommendation, which became $100 \%$ in all groups.

\section{Conclusions:}

The main finding was that perfusion measurements made by different observers were consistent, regardless of the level of experience in burn care. Nevertheless, the clinical assessment varied considerably between the observers, even though they had access to accurate predictions from the perfusion measurements. An important reason for ignoring the perfusion-based predictions was uncertainty of the meaning of the perfusion values. This highlights the need for experience with LSCI before it can be expected to produce good results. 


\section{Paper IV}

\section{Purpose:}

The goal with this study was to investigate if cardiac vasomotion could be used to improve burn depth assessment. We also wanted to determine the optimal measurement duration needed for vasomotion-based assessment.

\section{Results:}

Reproducibility was tested for measurement durations between 1 and 12s. Longer measurement durations had higher reproducibility. After a duration of $8 \mathrm{~s}$, further improvements in reproducibility were small and not deemed clinically relevant. Measurements of $8 \mathrm{~s}$ had a CV of $15.9 \%$ compared to a CV of $12.1 \%$ for 12 -second measurements. The shortest measurement duration with a CV near $20 \%$ was the 4second measurement with a $\mathrm{CV}$ of $20.7 \%$. A 4-second measurement was therefore considered as the shortest measurement duration to produce reliable results.

A total of 187 ROI from 32 patients were analyzed. For the first time, we were able to show that cardiac vasomotion and perfusion could be combined into a pulsatility measurement which could accurately predict surgical need day 0-2.

Perfusion in burns healing in 3-20 days was significantly lower on day 0-2, 311 PU (95\% CI: 280-341 PU), compared to perfusion values on day 3-5, 398 PU (95\% CI: 367-429 PU) ( $\mathrm{p}=0.006)$. There was no significant difference in pulsatility in burns healing in 3-20 days, $10.7 \mathrm{PU}^{2}$ (95\% CI: 8.8-12.6 $\left.\mathrm{PU}^{2}\right)$ day 0-2 compared to $13.5 \mathrm{PU}^{2}$ (95\% CI: 11.6-15.4 $\left.\mathrm{PU}^{2}\right)$ day 3-5 $(\mathrm{p}=0.45)$.

In burns that required surgery, both perfusion and pulsatility were significantly lower compared to burns that healed spontaneously within 20 days. Perfusion on day 0-2 was 84 PU (95\% CI: 77-91 PU) compared to 106 PU (95\% CI: 84-128 PU) on day 3-5 (p>0.99). Pulsatility values were $0.64 \mathrm{PU}^{2}$ (95\% CI: $\left.0.52-0.76 \mathrm{PU}^{2}\right)$ on day 02 and $1.14 \mathrm{PU}^{2}$ (95\% CI: 0.56-1.72 $\mathrm{PU}^{2}$ ) on day 3-5 (p>0.99). Pulsatility could accurately differentiate wounds that required surgery from wounds that healed after 12-20 days.

ROC curves were constructed for all individual 8-second measurements and the optimal cut-off was at $<2.13 \mathrm{PU}^{2}$ giving a sensitivity of $100 \%$ (95\% CI: $88.1-100 \%$ ), a specificity of $98.8 \%$ (95\% CI: 95.7-99.9\%), a PPV of $94.7 \%$ and an NPV of $100 \%$. We were also interested to see how the 4-second measurements would perform and 
constructed ROC curves for them too. The most optimal cut-off at $<2.25 \mathrm{PU}^{2}$, had a sensitivity of $97.3 \%$ (95\% CI: 90.6-99.7\%), a specificity of $94.0 \%$ (95\% CI: $91.3-$ $96.1 \%$ ), a PPV of 77.8, and an NPV of 99.4. The ROC curves can be seen in figure 13 .

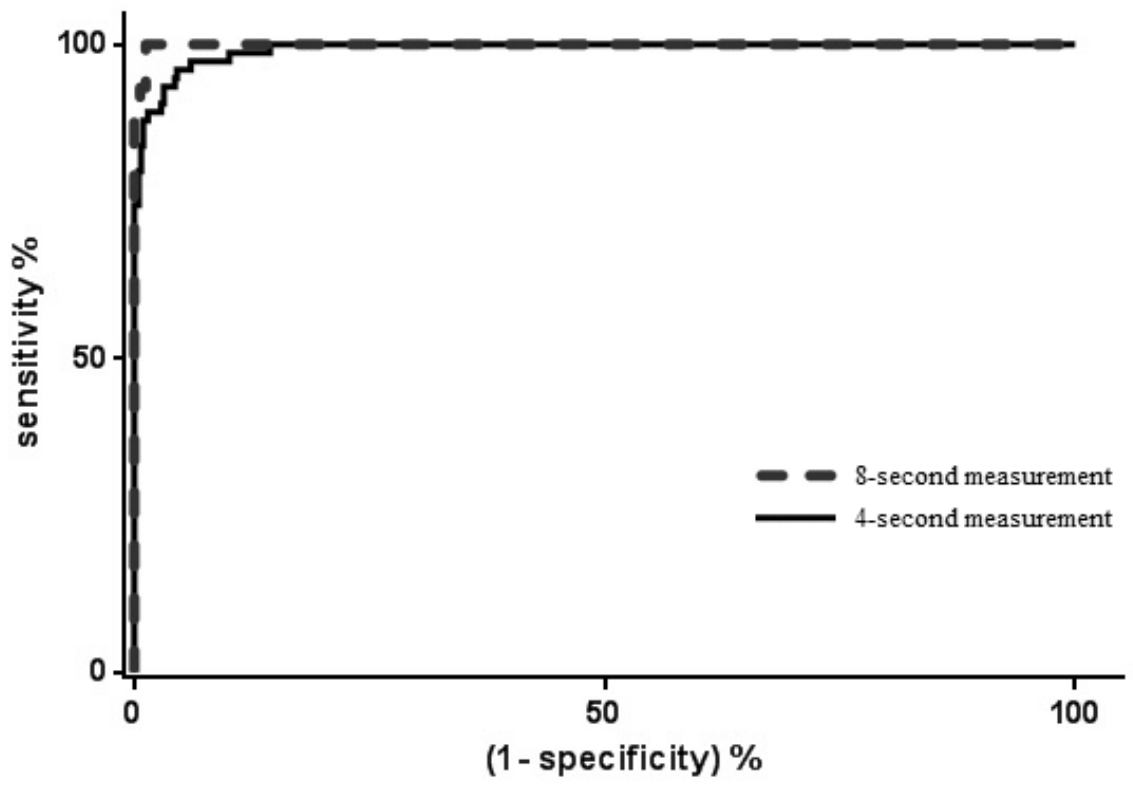

Figure 13. Receiver operator characteristics (ROC) curve of pulsatility with different measurement durations and sensitivity/specificity to detect surgical need. Sensitivity is seen on the $y$-axis and inversed specificity on the x-axis. The thinner line corresponds to 4-second pulsatility measurements and the thicker dotted line to 8 -second measurements.

Finally, we wanted to investigate the difference in accuracy between single measurements based on perfusion and pulsatility. We used the previously established cut-offs from paper II, and this resulted in an accuracy of 89.8\% (95\% CI: 87.1$92.5 \%$ ) compared to an accuracy of $94.5 \%$ (95\% CI: 92.5-96.5\%) with the 4-second measurement. An 8-second measurement however achieved an accuracy of $99.0 \%$ (95\% CI: 97.5-100\%). 
The following formula was used to calculate pulsatility, where $\bar{P}$ is the average perfusion in PU, $p(k)$ the perfusion value of the $k^{\text {th }}$ measurement point in PU, and $N$ the number of measurement points:

$$
\text { Pulsatility }=\frac{\bar{P}}{10^{3}} \times \frac{1}{N} \sum_{k=2}^{N}|p(k)-p(k-1)|
$$

\section{Scout scan}
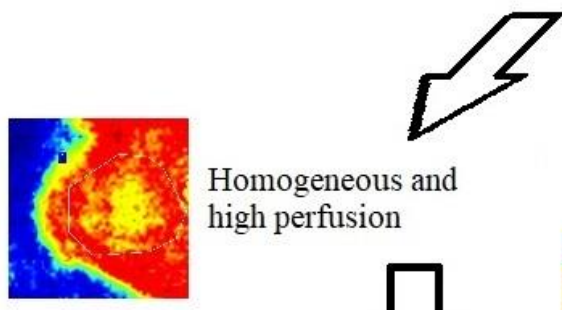

Homogeneous and high perfusion
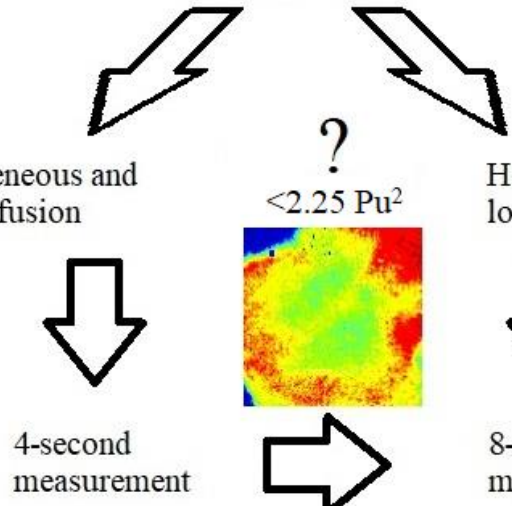

$<2.25 \mathrm{Pu}^{2}$
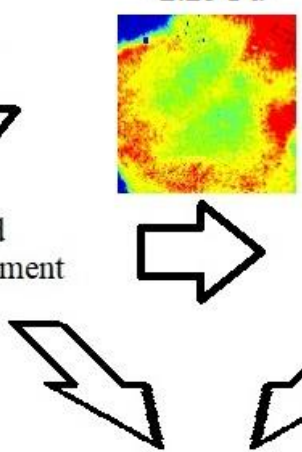

Spontaneous

healing
Heterogeneous and low perfusion

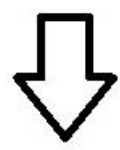

8-second measurement

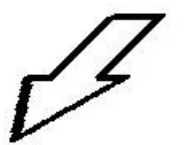

Early surgery

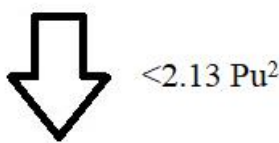

Figure 14. Suggested flowchart based on the findings in paper IV. If there is clinical suspicion of deep wound areas, a perfusion scout scan should be done. If the scout scan has clear areas of low perfusion, an 8-second measurement should be done. If perfusion is homogeneous and high, a 4second measurement is enough. If the 4-second measurement shows a reduced pulsatility or reveal suspicious areas that were overlooked in the scout scan, a full 8-second measurement should be done. When measurements are done, it should be clear whether spontaneous healing within 3 weeks is expected or not. If not, surgery of the slow healing areas can be planned. 
The primary finding was that pulsatility correlates to surgical need day 0-2 after injury. We could also show that pulsatility does not change over time in the same way as perfusion. This makes pulsatility less time dependent than the previously optimal method established in paper II with a measurement on day 0-1 and day 3-4. Finally, we could also show that a 4-second measurement would be enough for routine screening and that an 8-second measurement is only needed when initial images indicate low perfusion areas suggestive of surgical need. Based on these findings we suggest the clinical approach described in figure 14 . 


\section{Discussion}

\section{Main findings}

The main finding in this thesis is that LSCI can be used to determine surgical need in burns. We have also described the perfusion dynamics in wounds of different healing time. This is important to improve the understanding of wound healing, but also to provide us with optimal measurement times to evaluate surgical need. This laid the foundation for the time-window for single measurement with LSCI and that two measurements could improve accuracy if timed properly. The interobserver differences of LSCI are very small in regards of perfusion and with the training, the same could become true for the assessments. Finally, we were able to show that pulsatility adds to the diagnostic value of LSCI. These findings also have important implications for LDI and when deciding the measurement duration of LSCI-recordings within all research areas.

Cardiac vasomotion is the largest contributor to changes in perfusion during short time intervals. If LSCI is used to capture perfusion images with a total exposure time that is shorter than the cardiac cycle, the value will likely not be reproducible. This also creates a large problem with all LDI system, as these calculate perfusion by scanning the wound. This means that some areas will be scanned when the cardiac cycle causes the perfusion to be at its highest, while other areas will be scanned at the lowest values. Since cardiac vasomotion is diminished in deep partial-thickness, this is less of a problem for these wounds. Wound of intermediate partial-thickness, if captured during the diastolic phase, could easily be mistaken for deep partial-thickness burns, however.

\section{Perfusion dynamics in scald burns}

In the first paper, the aim was to investigate perfusion dynamics in scald burns. The results show that scalds with a short healing time had a very sharp increase in perfusion the first few days after injury. This state of high perfusion quickly subsided, however. In figure 9, it can be seen how the perfusion over time looks a bit like a single peak in superficial partial-thickness burns and turns into a double peak/hill in scalds of more intermediate thickness. The second peak/hill also tends to become more separated from the first peak/hill, and there is a clear diminishing effect, particularly on the first peak/hill which likely correlates to an early inflammatory response. This might indicate the presence of specific underlying processes in the wounds which 
indirectly or directly affect the perfusion. Another important question to consider is whether these perfusion dynamics and underlying mechanisms differ among burn types.

Another interesting question, which was never truly answered, is how large the perfusion variations in burns are during the entirety of a day. This would be interesting to further investigate which could potentially be achieved by using a laser Doppler probe attached to the wound underneath the wound dressing. Even if the generated data would only be from a small area, and potentially have some degree of sampling error, if repeated in several patients the average value would be useful. In a setup like this, it would also be possible to study the desynchronized aspects of vasomotion and to investigate endothelial dysfunction in burns. It is possible that the perfusion variations over 24 hours in burns are substantial and could be used to improved diagnostics further than the methods presented in this thesis.

Single measurement and double measurement to determine surgical need

The focus of the second paper was to establish the accuracy of LSCI measurements and whether two separate measurements would be beneficial. As previously know from LDI, we could show that single measurements 3 days after injury had a high accuracy to predict surgical need. As expected, early measurements had much lower accuracy, but a high NPV. The addition of two measurement points was successful, and the double measurement was able to correctly assess all included cases. In many ways, this was quite expected when looking at the perfusion dynamics presented in figure 9 , as the perfusion differences between the different healing times is pronounced the first few days after injury. The major finding in this study was therefore that surgical need could be evaluated with LSCI and that two measurements are better than one.

Based on these findings, LSCI can be considered a valuable addition to early burn diagnostics. The easiest way to use LSCI would be to capture initial perfusion images as soon as possible in all patients. If homogenous zones of perfusion $<240 \mathrm{PU}$ are identified, a new measurement should be done around day 3-4. From our current understanding of perfusion dynamics, this window could likely be extended to 2-5 days, although we lack the data to back this claim. If the second measurement shows a clear decrease in perfusion from the first measurement, it is a sign of burn wound conversion. In these cases, it would be best to put the perfusion values into the formula presented in paper II. If the value is close to $-0.35 \mathrm{mod}$ PU/hour, surgery should be considered. A flow chart of this reasoning can be seen in figure 10. 
There are however many other factors that must be considered when deciding something as important as surgery or no surgery. How large is the area of the low perfusion zone? Is it localized over a major joint? Is there more than one zone with low perfusion that might need surgery? Does the patient have any comorbidities? When these questions have been answered the best course of action has to be construed. If surgery is the most appropriate course of action, the type of surgical procedure must also be considered. Excision and suture can be a good choice for smaller wounds but might fail in slightly larger wounds where a split-thickness graft would be more suitable.

For the abovementioned reasons, decisions need to be based on clinical aspects and cannot be reduced to a value provided by a simple formula. LSCI should therefore be used as a tool, which gives us enhanced vision and helps us to understand the expected development of the wound.

\section{Interobserver variation in $\mathrm{LSCl}$}

The aim of the third paper was to test inexperienced LSCI-observers' ability to interpret perfusion images and their ability to convert the perfusion data into a correct assessment of the burn. As previously mentioned, decision making cannot rest on perfusion values alone; the entire clinical situation must be considered. We therefore wanted to investigate both the interobserver variation of perfusion values and of clinical assessments. The agreement of perfusion values should be considered as an optimal scenario of how well the agreement of clinical assessments could be. Our results showed that the agreement of perfusion values was very high, with only a few outliers (see figure 11). The interobserver variation of perfusion values did not result in different LSCI recommendations, and it's reasonable to assume that these variations would have no clinical impact.

The clinical assessments however, had a low agreement (see figure 12). There are likely several reasons why observers differed so much in their clinical assessments. One important reason could be that the observers generally decided to trust something they recognize, which means many observers put too much emphasis on the visual appearance of the wound in the RGB image. This is a mistake, as it is hard to evaluate healing potential based on an RGB image. Additionally, the RGB-image was often captured within the first 24 hours after injury. This made it even harder to us the RGBimage for diagnostic purposes.

Because the observers were inexperienced with LSCI, they were unable to fully understand the perfusion images. This was likely a major reason behind the variation 
of clinical assessments and a short presentation and an information pamphlet will not change that. Even though the observers received a recommendation, it was very hard for them to evaluate its meaning. This might be one of the primary reasons behind the superior performance of the junior doctors in this study. They likely relied less on the RGB image and were more inclined to follow the recommendation as they had a limited understanding of burn care.

The results from paper III highlight the need to develop a thorough understanding of perfusion images among the clinical staff. Until this is done, LSCI cannot be introduced as a clinical tool for early burn assessment. There needs to be a transition phase where LSCI measurements are gradually introduced into standard clinical practice. The results from the first few LSCI measurements should however not be acted upon. This approach would give time for the surgeons to develop their understanding of the system and build trust to the perfusion images. After some time, the surgeons will feel comfortable with perfusion images and wish to use this information for early interventions.

\section{Pulsatility}

The objectives of the fourth paper was to investigate if the cardiac vasomotion could be used in combination with perfusion to create a pulsatility measurement and improve the diagnostic potential. Using this method, we could show that the temporal dynamics of pulsatility are less pronounced than that of perfusion. The timing of the measurement is therefore not as important as for the previously suggested methods. This makes the method easier to use in clinical practice, as many patients visit the burn clinic outside the required time window described in paper II. Particularly in countries with large distances, like Sweden, transportation time will often cause delays, which sometimes makes it difficult to examine the patient the same day as the injury occurred. It is therefore important to have a method without variation in accuracy the first few days after injury.

The pulsatility method however has one large drawback. It might be somewhat user dependent. To make successful measurements a quick scout scan must first be done. Afterwards the material must be evaluated, suspicious areas identified and measured again. This approach substantially reduces recording duration which is a necessity in a clinical situation.

In paper IV, an experienced LSCI-user (the author) made all measurements. Often it was possible for the LSCI-user to evaluate the images as they were captured (both perfusion and pulsatility aspects) to quickly understand what would be interesting to 
look closer at. This cannot be expected of less experienced LSCI-users, who might need more time to go through the material. However, in $60-80 \%$ of the cases, a 4 second measurement of a typical perfusion area will be enough to rule out surgical need.

In a typical scald of 10-15 \% TBSA with 2-3 wounds, a scout view would consist of 4-5 images. A 4-second measurement would then have to be made of the areas with the lowest perfusion. The total time to capture the images and to evaluate them on the spot should not require more than 1-2 minutes. The most critical part would be motion artefacts during the 4-second measurements. Smaller motion artefacts during the scout view is of no consequence, if the observer is experienced enough.

There are however several aspects that require more work before pulsatility is ready for further clinical studies. The algorithm itself might need optimization when more data has been collected to retest the algorithm. Such an optimization could also reduce the measurement time while preserving adequate accuracy.

Pulsatility was primarily developed with data from scalds. Only $6.25 \%$ of the data was obtained from contact burns. The mechanisms of pulsatility in burns of other mechanisms than scalding therefore requires further study.

\section{Limitations}

LSCI as a method has several limitations. Many of these limitations are technical, but there are also several limitations in our study design which need to be considered when evaluating our results.

\section{Technical LSCl-limitations}

LSCI measures perfusion, and not actual blood flow. If we measured blood flow, we could specify this into SI-units such as $\mathrm{mL} / \mathrm{kg} / \mathrm{min}$. As we want to measure the blood flow non-invasively, we must therefore settle for an indirect surrogate measure, which has a correlation to the true blood flow. This is associated with several issues: 
1) We do not know the exact penetration of laser light into the tissue

2) Perfusion does not have a perfect correlation to actual blood flow.

3) We do not know from which depth the perfusion signal arises.

To further explain, the same vessel, with the same blood flow will give rise to different perfusion signals depending on its depth in the tissue from the measurement surface. Therefore, two different ROI, but with the same perfusion value could come from two wounds that look quite different histologically. This is likely the reason why early single measurements have a lower accuracy since it is not possible to tell from which vascular plexuses the measured perfusion value originates.

There are also other technical aspects. Depending on the moistness off the wound surface, there is always a risk for specular reflections. This means that large amounts of the laser light reflect directly on the surface and will not be blurred by moving chromophores. The result is an overexposed and very static image, which often translates to negative perfusion values by the software calculation.

The LSCI equipment used in this study attempts to mitigate this problem using a cross-polarizing filter in front of the camera. A laser produces coherent light, mainly in a single polarization plane, although this can be further improved by placing a polarization filter at the aperture of the laser, at the cost of the power of the laser. Placing a cross-polarized filter in front of the camera eliminates most specular reflections, but in certain conditions, reflections can still be an issue and cause a reduction on the perfusion signal. A reduction of 20-40 PU could in some cases have serious implications when evaluating surgical need.

Motion artefacts are a common and significant problem. Any movement of the target tissue will increase the perfusion signal as the LSCI cannot separate internal from external movement of the measured chromophore. This means that motion artefacts will always increase the measured perfusion value. In a way, this makes motion artefacts easy to understand and detect. In a series of images, the one with the lowest perfusion should therefore have the least motion artefacts. One issue is the cardiac vasomotion however, which adds a variation to the true perfusion signal. The image in the series with the lowest perfusion might therefore not be the image with the least motion artefacts, it will however be among the images with the fewest motion artefacts. 
A second way to detect motion artefacts is by looking at structures in the image and perfusion borders. If all structures are sharp and there are clear perfusion borders somewhere in the image, the motion artefacts are likely small.

The most common cause of motion artefacts is breathing, which we do like to see in our patients. There is therefore an anatomical pattern in motion artefacts, the largest occurring in the thorax, then abdomen, and then throat/cheek/lips. The second most common reason for motion artefacts comes from the choice of anesthesia, which in children often is ketamine/esketamine. This means that the patient will move around during the procedure. The key to a good LSCI measurement is to time the recording between these movements and to make sure there is no pain stimuli while perfusion images are recorded.

A third issue is the presence of shadows. These arise because the laser and camera are placed with a slight angle between them. Since the LSCI-camera receives very little light from the shaded areas, they will be underexposed. This means that the contrast will be very poor, and the software will interpret this as areas of high perfusion. These shadows never present a problem in routine usage but may sometimes confuse inexperienced LSCI-users who have not seen these shadows before.

Another technical issue is the presence of other light sources in the room where the LSCI-camera is used. Current commercially available LSCI-cameras uses a diode laser at $785 \mathrm{~nm}$. Modern lights produce mostly visible light, but old lamps typically have a very wide spectrum, with a substantial part of the energy in the near-infrared spectrum of 2500-750 nm. This type of lamp sometimes exists in older operating theatres, and one should be aware of the risk of interference with the measurements.

\section{Study related limitations}

There are also several limitations which are more specific to the studies included in the thesis. Many of these limitations are shared between the different studies while others are limited to a specific study.

Most wounds were located on the upper part of the torso, the arms, and the thighs. This means that the conclusions in these studies are mostly based on wounds from these anatomical regions. There is a known variation in baseline perfusion in different areas of the body and perfusion response after provocations also seem to vary [76]. The results presented in this thesis should therefore be used with care for areas such as palms, soles, and face since optimal cut-offs might be slightly different. 
Anecdotally, we believe there is decreased perfusion with increasing age. Few adults have been included in our studies and we do not have the data to verify this suspicion. It is however an important aspect as it could affect cut-offs. The most likely reason behind this suspected variation would be differences in dermal and epidermal thickness, and microcirculatory changes with age.

In older patients, comorbidities also present a problem. The presence of diseases such as diabetes and neuropathies and their influence on perfusion measurements with LSCI in burns have not been studied. In addition to this, lifestyle choice as smoking and snuff could also have a large impact on perfusion values through the nicotine content.

Hypertension is a common problem in the adult population and how this affects perfusion measured with LSCI in burns is unknown. If using pulsatility as a measurement, the impact may be large. In our studies, we have never investigated the blood pressure during measurements. When doing measurements with LDF, it is common to have continuous blood pressure measurement so this can be connected to the LDF signal and generate a perfusion value described as AU/mmHg. In many ways, the lack of blood pressures can be considered an important limitation. Most of our patients however consists of young toddlers without any known conditions. It is therefore reasonable to assume that most patients would have had a normal blood pressure. There are however aspects such as anesthesia, which can have a large effect on the blood pressure. As these routines might differ between burn centers it is vital to investigate the impact of blood pressure on perfusion recordings done with LSCI.

In all of our studies, healing time was defined based on clinical examination and evaluation of images. Interobserver variation when determining degree of reepithelialization is a known issue. Since there were images of most wounds, it was however possible for the same observer to judge the degree of reepithelialization and compare it to the $100 \%$ reepithelialization date from the journal records. We believe this method assured consistency and would not cause the recorded healing time to differ more than 2 days from the actual healing time.

No biopsies were used. This means our measurements could not be compared to the current gold standard. However, since surgery was delayed for at least 14 days after injury, the observation time was long enough to verify whether the burn was superficial or deep partial-thickness. The decision to delay surgery to at least 14 days after injury was not done on account of the presented studies, but rather based on a policy decision made a long time ago. This however created unique opportunities as biopsies generally are out of question and because most other burn centers make surgery decisions much earlier. 
There are also some limitations with data processing in the studies. All ROI in the studies have been marked by the same researcher. The high agreement of perfusion values between different observers in paper III has helped to alleviate some of these concerns. However, selection bias when creating ROI might have affected the results in the studies and there is a need to investigate this. The simplest way to achieve this would be to have at least two different LSCI-users assess the same images and compare their conclusions. This study would have to be performed with experienced LSCI-users, preferably also with burn surgery experience. As such, the suggested study is not possible to conduct as of now.

The formulas developed in paper II and IV have also been fitted to all available data. This means that there was no untested data which could be used to evaluate the performance of a theoretical new data set. This means that the high precision in these formulas might be slightly overestimated as it is not certain they would perform as well in a new material. There is therefore a need to retest these formulas on new databases and to adjust as necessary. For these reasons, the formulas presented in paper II/IV should be considered as preliminary formulas as they may need more work to make them truly optimal for a larger patient material.

The pulsatility formula presented in paper IV also has a frequency problem. Since it uses cardiac vasomotion to calculate pulsatility, the pulse rate has a large effect on the result. This needs to be considered particularly in animal models where the pulse rate could be a lot higher, and our sampling frequency too low to capture cardiogenic vasomotion. This means that measurement duration could be decreased in some animal models, as the number of heart cycles is important for reproducibility and not time itself.

Pulse rate was not continuously monitored through pulse oximetry or some other method and could therefore not be correlated to the pulsatility signal. The sampling frequency was also much lower $(5.25 \mathrm{~Hz})$ compared to pulse oximetry (around $500 \mathrm{~Hz}$ ), which makes the pulsatility signal appear noisy. The pulse rate also affects the calculated pulsatility. One easy way to avoid the effect of pulse rate variation would be to use the amplitude, but this would create a new problem. The deep partial-thickness burns typically has a chaotic signal and often showed a high amplitude sporadically. In the superficial partial-thickness burns, the amplitude shifts were recurring and predictable. As such, how often the amplitude shifts occur seem as important as their amplitude. We therefore believe that the frequency aspect is important even though other factors such as age and clinical condition affects it.

If we for simplicity's sake assume that the perfusion signal from cardiac vasomotion is a sine wave, the Nyquist rate must be considered. This means that the sampling rate should be at least twice the frequency of the measured signal, which 
gives an upper limit of $157.5 \mathrm{bpm}$ with the frequency we used $(5.25 \mathrm{~Hz})$. In paper IV the pulse rate was not recorded, but all patients were connected to a pulse oximetry during dressing procedures. A pulse rate as high as $157.5 \mathrm{bpm}$ would have caused a slight commotion and would have alerted the LSCI operator to any such issues.

If the pulse rate was recorded before the LSCI measurement, the measurement protocol/duration could be adjusted to the pulse rate of the patient which could decrease measurement duration without affecting the accuracy of measurements.

\section{Areas of further research}

Before LSCI can be considered a full fledge utility in the toolbox of every burn surgeon, much needs to be done. The most notable problems are things like the effect of age, blood pressure, nicotine, diabetes, and neuropathy on perfusion in burns. LSCI also needs to be more thoroughly evaluated for burns of all mechanisms of injury. There is a need to verify the formulas presented in paper II/IV in a larger material. Although this may seem daunting, many of these aspects have not been investigated in LDI, which does not seem to hinder the technique from routine usage in several burn centers. The effects of early surgery based on LSCI measurements also need to be evaluated in a prospective study. Aspects such as days to wound closure, rate of infection, long term evaluation of scars, and cost aspects would all be interesting to investigate. If a prospective study can show obvious benefits with LSCI, it should be accepted as a method alongside LDI.

The exact method for surgery is also worth contemplating. Small burns $<2 \mathrm{~cm}$ in diameter seem to behave slightly different than the larger burns. Despite quite low perfusion values, often below the cut-off for surgery, they seem to heal slightly faster than expected. The reason behind this could be related to the small area and the fact that adjacent microcirculation is still healthy. The question is: what happens if we try to recreate this environment? Imagine we have a circular wound with a diameter of 5 $\mathrm{cm}$. Day 2, surgery is done with excision and split-thickness grafting corresponding to a circle with a diameter of $3.5 \mathrm{~cm}$ centrally placed in the $5 \mathrm{~cm}$ diameter wound. This would leave a surrounding area of $1.5 \mathrm{~cm}$ around the area of split-thickness grafting, where only restrictive surgical debridement would be done. Would this facilitate healing of the surrounding area or would the transplant in the middle fail because we left the adjacent area without transplant? If we look at the numbers, the transplanted area would be $9.6 \mathrm{~cm}^{2}$ compared to an actual wound area of $19.6 \mathrm{~cm}^{2}$. The technical issues with graft collection aside, a method like this could be used to reduce the size of surgery. 
To be able to determine the burn depth on the day of the injury also opens for nonsurgical interventions. Recent studies have shown that pentoxifylline, which is a nonselective phosphodiesterase inhibitor and when given intra peritoneally, can be used in rats to salvage the zone of stasis in contact burns [77]. This means that burns with a low pulsatility the same day as injury could potentially receive non-surgical treatment. The measurement could then be repeated on day 3 to assess if the treatment was effective. If not, the surgical delay would still be short. Non-surgical intervention is an interesting prospect, particularly in smaller burns where a successful treatment would avoid the need for surgery altogether. A pulsatility measurements would make it possible to determine which patients might gain from such treatment and help make non-surgical treatments a cost-effective method.

Finally, it remains to be seen if pulsatility as a measurement has a value within other fields of microcirculation or if its use is restricted to burn diagnostics. Nonetheless, the large variations in perfusion over the cardiac cycle should be considered when LSCI is used to measure perfusion with a measurement duration shorter than the pulse rate. This particularly needs to be considered when using LDI, as the final perfusion image will contain information from different phases of the cardiac cycle, and it might not be possible to know the true average perfusion for individual spots.

Perfusion as a measurement is also associated with the problem that we do not measure blood flow, but rather arbitrary units which correlate with the blood flow. It is therefore interesting to continue work on understanding which vascular compartment different parts of the signal originates from. Pulsatility might have a high accuracy because it can differentiate between damage of the deep and superficial plexuses where a vital microcirculation is required to achieve rapid spontaneous healing.

\section{Future perspectives}

In this project, several methods have been developed to evaluate healing potential in burn wounds and we have been able to establish that LSCI is a promising diagnostic tool for burns. Many questions remain and there is a need of more studies, however. The most important aspect right now would be a prospective study, to evaluate how much these early interventions would improve the result in patients. This presents us with several hurdles. All burn surgeons that would participate in such a project would have to become well acquainted with the LSCI system. If the surgeons do not trust the system, they would never dare to operate on a burn only 1-2 days old, and rightly so. 
The potential gain for the patient is substantial though. Much faster healing times, fewer changes of dressing, less anesthesia for the patient, and little time to develop wound infections. The method would be cost effective for the clinic and save many hours of precious operating theater time.

Even though the use of LSCI in clinical practice would mean much work, it seems to be the future and must be introduced to not fall behind burn centers already using LDI. Considering the benefits with LSCI compared to LDI, a burn center using LSCI could benefit even more.

As previously mentioned in the discussion, there are non-surgical approaches which can reduce the risk of surgical need. These methods are still at an early stage, but once they have been further developed; it is important to have well-developed methods for early burn diagnostics.

Hopefully, the description of pulsatility can become useful within other fields of research and possibly be used alongside perfusion to better understand what is actually going on in the microcirculation. 


\section{Conclusions}

\section{Paper I}

In this paper, we could describe how perfusion dynamics varied in relation to healing time. Superficial partial-thickness burns had a sharp increase in perfusion followed by a quick decrease. With increased healing time, these dynamics were diminished and wounds with surgical need had a decrease in perfusion after presentation that did not recover until 11 days after injury. With this data we could conclude that the optimal measurement window was between day 3 to 5 after injury when the differences in perfusion was the largest between wounds of different healing times. The potential advantages with an early and a late measurement were also discussed.

\section{Paper II}

In this study, we were able to show that LSCI can predict surgical need 3-4 days after injury with a high accuracy. We could also establish that there was no significant difference whether the measurement was done day 3 or day 4 . We were also able to show that the same was true for measurements within the first 24 hours after injury. Finally, we could show that a double measurement approach further improves accuracy, as this considers blood flow dynamics in the wound.

Paper III

LSCI interobserver differences in perfusion values are small. Regardless of this, the actual assessment selected by the observers varied a lot and the agreement was poor. This highlights the need for the observer to understand the meaning of the measured perfusion values and to be able to interpret the images they are assessing. If all observers had this understanding, the assessments could have as high degree of agreement as the perfusion values. 


\section{Paper IV}

Pulsatility measured with LSCI is a reliable method to evaluate surgical need on day 02 after injury. We could show that pulsatility does not change over time in the same way as perfusion. This makes pulsatility less time dependent than static perfusion images. Finally, we could show that a 4-second measurement is enough for routine screening and that an 8-second measurement is only needed when low perfusion areas are present. 


\section{Acknowledgements}

This project has been a long and interesting journey. I'm grateful for all aid I have received from my supervisors. I appreciate the free reins I have been given, allowed to dabble in all sorts of things. To discovery and uncover something new has always been dear to me. I also want to thank everyone at Linköping burn center. Their work has been essential for this thesis and I hope its results will repay them in kind.

Tack ni som lyssnar på mina ändlösa diskussioner om för er inte särskilt intressanta ämnen. Tack för att ni kommer med synpunkter som hjälper mig att komma vidare och förstå nästa steg. Tack för att ni orkar med mig. Älskar er!

想像力の様に, 君はいつだって此処に居る

僕らは赤い系で繋いでいて

本当に 39 


\section{References}

[1] D'Orazio J, Jarrett S, Amaro-Ortiz A, Scott T. UV Radiation and the Skin. Int J Mol Sci. 2013 Jun; 14(6): 12222-12248. Published online 2013 Jun 7. doi: 10.3390/ijms140612222

[2] Boer M, Duchnik E, Maleszka R, Marchlewicz M. Structural and biophysical characteristics of human skin in maintaining proper epidermal barrier function. Postepy Dermatol Alergol. 2016 Feb;33(1):1-5. doi: 10.5114/pdia.2015.48037. Epub 2016 Feb 29.

[3] Driskell RR, Jahoda CA, Chuong CM, Watt FM, Horsley V. Defining dermal adipose tissue. Exp Dermatol. 2014 Sep;23(9):629-31. doi: 10.1111/exd.12450.

[4] Munger BL, Ide C. The structure and function of cutaneous sensory receptors. Arch Histol Cytol. 1988 Mar;51(1):1-34.

[5] Biedermann T, Pontiggia L, Böttcher-Haberzeth S, Tharakan S, Braziulis E, Schiestl C, Meuli M, Reichmann E. Human eccrine sweat gland cells can reconstitute a stratified epidermis. J Invest Dermatol. 2010 Aug;130(8):1996-2009. doi: 10.1038/jid.2010.83. Epub 2010 Apr 8.

[6] Braverman IM. The cutaneous microcirculation. J Investig Dermatol Symp Proc. 2000 Dec;5(1):3-9.

[7] Nagasaka T, Hirata K, Nunomura T. Contribution of arteriovenous anastomoses to vasoconstriction induced by local heating of the human finger. Jpn J Physiol. 1987;37(3):425-33.

[8] Heimbach D, Engrav L, Grube B, Marvin J. Burn depth: a review. World J Surg. 1992 Jan-Feb;16(1):10-5.

[9] Svee A, Jonsson A, Sjöberg F, Huss F. Burns in Sweden: temporal trends from 1987 to 2010. Ann Burns Fire Disasters. 2016 Jun 30;29(2):85-89.

[10] Heimbach D, Engrav L, Grube B, Marvin J. Burn injury: review of pathophysiology and therapeutic modalities in major burns. World J Surg. 1992 JanFeb;16(1):10-5.

[11] Battle CE, Evans V, James K, Guy K, Whitley J, Evans PA. Epidemiology of burns and scalds in children presenting to the emergency department of a regional burns unit: a 7-year retrospective study. Burns Trauma. 2016 Jun 21;4:19. doi: 10.1186/s41038-016-0047-7. eCollection 2016. 
[12] Hall AH, Mathieu L, Maibach HI. Acute chemical skin injuries in the United States: a review. Crit Rev Toxicol. 2018 Sep 18:1-15. doi:

10.1080/10408444.2018.1493085. [Epub ahead of print]

[13] Hardwicke J, Hunter T, Staruch R, Moiemen N. Chemical burns--an historical comparison and review of the literature. Burns. 2012 May;38(3):383-7. doi: 10.1016/j.burns.2011.09.014. Epub 2011 Oct 28.

[14] Shih JG, Shahrokhi S, Jeschke MG. Review of Adult Electrical Burn Injury Outcomes Worldwide: An Analysis of Low-Voltage vs High-Voltage Electrical Injury. J Burn Care Res. 2017 Jan/Feb;38(1):e293-e298. doi: 10.1097/BCR.0000000000000373.

[15] Alharbi Z, Piatkowski A, Dembinski R, Reckort S, Grieb G, Kauczok J, Pallua N. Treatment of burns in the first 24 hours: simple and practical guide by answering 10 questions in a step-by-step form. World J Emerg Surg. 2012 May 14;7(1):13. doi: 10.1186/1749-7922-7-13.

[16] Devgan L, Bhat S, Aylward S, Spence RJ. Modalities for the assessment of burn wound depth. J Burns Wounds. 2006 Feb 15;5:e2. doi: 10.1016/j.burns.2008.01.009.

[17] Monstrey S, Hoeksema H, Verbelen J, Pirayesh A, Blondeel P. Assessment of burn depth and burn wound healing potential. Burns. 2008 Sep;34(6):761-9. doi: 10.1016/j.burns.2008.01.009.

[18] Medina JL, Fourcaudot AB, Sebastian EA, Shankar R, Brown AW, Leung KP. Standardization of deep partial-thickness scald burns in C57BL/6 mice. Int J Burns Trauma. 2018 Apr 5;8(2):26-33. eCollection 2018.

[19] Jackson DM. The diagnosis of the depth of burning. Br J Surg. 1953 May;40(164):588-96.

[20] Smolle C, Cambiaso-Daniel J, Forbes AA, Wurzer P, Hundeshagen G, Branski LK, Huss F, Kamolz LP. Recent trends in burn epidemiology worldwide: A systematic review.Burns. 2017 Mar;43(2):249-257. doi: 10.1016/j.burns.2016.08.013. Epub 2016 Sep 3.

[21] Lee KC, Joory K, Moiemen NS. History of burns: The past, present and the future. Burns Trauma. 2014 Oct 25;2(4):169-80. doi: 10.4103/2321-3868.143620. eCollection 2014.

[22] Lund C, Browder NC. The estimation of areas of burns. Surg Gynecol Obstet. 1944;79:352-8. 
[23] Wallace AB. The exposure treatment of burns. Lancet 1951:501-4.

[24] Rossiter ND, Chapman P, Haywood IA. How big is a hand? Burns. 1996 May;22(3):230-1.

[25] Kamolz LP, Lumenta DB, Parvizi D, Dirnberger J, Owen R, Höller J, Giretzlehner M. Smartphones and burn size estimation: "Rapid Burn Assessor". Ann Burns Fire Disasters. 2014 Jun 30;27(2):101-4.

[26] Sheng WB, Zeng D, Wan Y, Yao L, Tang HT, Xia ZF. BurnCalc assessment study of computer-aided individual three-dimensional burn area calculation. J Transl Med. 2014 Sep 10;12:242. doi: 10.1186/s12967-014-0242-x.

[27] Halgas B, Bay C, Foster K. A comparison of injury scoring systems in predicting burn mortality. Ann Burns Fire Disasters. 2018 Jun 30;31(2):89-93.

[28] Cubison TC, Pape SA, Parkhouse N. Evidence for the link between healing time and the development of hypertrophic scars (HTS) in paediatric burns due to scald injury. Burns. 2006 Dec;32(8):992-9. Epub 2006 Aug 8.

[29] Wang Y, Beekman J, Hew J, Jackson S, Issler-Fisher AC, Parungao R, Lajevardi SS, Li Z, Maitz PKM. Burn injury: Challenges and advances in burn wound healing, infection, pain and scarring. Adv Drug Deliv Rev. 2018 Jan 1;123:3-17. doi: 10.1016/j.addr.2017.09.018. Epub 2017 Sep 20.

[30] Roberts G, Lloyd M, Parker M, Martin R, Philp B, Shelley O, Dziewulski P. The Baux score is dead. Long live the Baux score: a 27-year retrospective cohort study of mortality at a regional burns service. J Trauma Acute Care Surg. 2012 Jan;72(1):2516. doi: 10.1097/TA.0b013e31824052bb.

[31] Devgan L, Bhat S, Aylward S, Spence RJ. Modalities for the assessment of burn wound depth. J Burns Wounds. 2006 Feb 15;5:e2.

[32] Kim LK, Martin HC, Holland AJ. Medical management of paediatric burn injuries: best practice. J Paediatr Child Health. 2012 Apr;48(4):290-5. doi: 10.1111/j.1440-1754.2011.02128.x. Epub 2011 Jun 17.

[33] Hoeksema H, Van de Sijpe K, Tondu T, Hamdi M, Van Landuyt K, Blondeel P, Monstrey S. Accuracy of early burn depth assessment by laser Doppler imaging on different days post burn. Burns. $2009 \mathrm{Feb}$;35(1):36-45. doi:

10.1016/j.burns.2008.08.011. Epub 2008 Oct 25.

[34] Thatcher JE, Squiers JJ, Kanick SC, King DR, Lu Y, Wang Y, Mohan R, Sellke EW, DiMaio JM. Imaging Techniques for Clinical Burn Assessment with a Focus on Multispectral Imaging. Adv Wound Care (New Rochelle). 2016 Aug 1;5(8):360-378. 
[35] Kaiser M, Yafi A, Cinat M, Choi B, Durkin AJ. Noninvasive assessment of burn wound severity using optical technology: a review of current and future modalities. Burns. 2011 May;37(3):377-86. doi: 10.1016/j.burns.2010.11.012. Epub 2010 Dec 23.

[36] La Hei ER, Holland AJ, Martin HC. Laser Doppler imaging of paediatric burns: burn wound outcome can be predicted independent of clinical examination. Burns. 2006 Aug;32(5):550-3. Epub 2006 May 24.

[37] Cho JK, Moon DJ, Kim SG, Lee HG, Chung SP, Yoon CJ. Relationship between healing time and mean perfusion units of laser Doppler imaging (LDI) in pediatric burns. Burns. 2009 Sep;35(6):818-23. doi: 10.1016/j.burns.2008.12.009. Epub 2009 May 6.

[38] Burke-Smith A, Collier J, Jones I. A comparison of non-invasive imaging modalities: Infrared thermography, spectrophotometric intracutaneous analysis and laser Doppler imaging for the assessment of adult burns. Burns. 2015 Dec;41(8):16951707. doi: 10.1016/j.burns.2015.06.023. Epub 2015 Sep 28.

[39] Hoeksema H, Baker RD, Holland AJ, Perry T, Jeffery SL, Verbelen J, Monstrey S. A new, fast LDI for assessment of burns: a multi-centre clinical evaluation. Burns. 2014 Nov;40(7):1274-82. doi: 10.1016/j.burns.2014.04.024. Epub 2014 Jul 1.

[40] McGill DJ, Sørensen K, MacKay IR, Taggart I, Watson SB. Assessment of burn depth: a prospective, blinded comparison of laser Doppler imaging and videomicroscopy. Burns. 2007 Nov;33(7):833-42. Epub 2007 Jul 5.

[41] Holland AJ, Martin HC, Cass DT. Laser Doppler imaging prediction of burn wound outcome in children. Burns. 2002 Feb;28(1):11-7.

[42] Stewart TL, Ball B, Schembri PJ, Hori K, Ding J, Shankowsky HA, Tredget EE; Wound Healing Research Group. The use of laser Doppler imaging as a predictor of burn depth and hypertrophic scar postburn injury. J Burn Care Res. 2012 NovDec;33(6):764-71. doi: 10.1097/BCR.0b013e318257db36.

[43] Baker RD, Weinand C, Jeng JC, Hoeksema H, Monstrey S, Pape SA, Spence R, Wilson D. Using ordinal logistic regression to evaluate the performance of laserDoppler predictions of burn-healing time. BMC Med Res Methodol. 2009 Feb 16;9:11. doi: 10.1186/1471-2288-9-11.

[44] Shin JY, Yi HS. Diagnostic accuracy of laser Doppler imaging in burn depth assessment: Systematic review and meta-analysis. Burns. 2016 Nov;42(7):1369-1376. doi: 10.1016/j.burns.2016.03.012. Epub 2016 May 20. 
[45] van Herpt H, Draijer M, Hondebrink E, Nieuwenhuis M, Beerthuizen G, van Leeuwen T, Steenbergen W. Burn imaging with a whole field laser Doppler perfusion imager based on a CMOS imaging array. Burns. 2010 May;36(3):389-96. doi: 10.1016/j.burns.2009.05.009. Epub 2009 Aug 27.

[46] Briers JD. Laser Doppler, speckle and related techniques for blood perfusion mapping and imaging. Physiol Meas. 2001 Nov;22(4):R35-66.

[47] Boas DA, Dunn AK. Laser speckle contrast imaging in biomedical optics. J Biomed Opt. 2010 Jan-Feb;15(1):011109. doi: 10.1117/1.3285504.

[48] Basak K, Manjunatha M, Dutta PK. Review of laser speckle-based analysis in medical imaging. Med Biol Eng Comput. 2012 Jun;50(6):547-58. doi: 10.1007/s11517-012-0902-z. Epub 2012 Apr 4.

[49] Jaskille AD, Shupp JW, Jordan MH, Jeng JC. Critical review of burn depth assessment techniques: Part I. Historical review. J Burn Care Res. 2009 NovDec;30(6):937-47. doi: 10.1097/BCR.0b013e3181c07f21.

[50] Jaskille AD, Ramella-Roman JC, Shupp JW, Jordan MH, Jeng JC. Critical review of burn depth assessment techniques: part II. Review of laser doppler technology. J Burn Care Res. 2010 Jan-Feb;31(1):151-7. doi: 10.1097/BCR.0b013e3181c7ed60.

[51] Sen CK, Ghatak S, Gnyawali SC, Roy S, Gordillo GM. Cutaneous Imaging Technologies in Acute Burn and Chronic Wound Care. Plast Reconstr Surg. 2016 Sep;138(3 Suppl):119S-28S. doi: 10.1097/PRS.0000000000002654.

[52] Clark A, Neyra JA, Madni T, Imran J, Phelan H, Arnoldo B, Wolf SE. Acute kidney injury after burn. Burns. 2017 Aug;43(5):898-908. doi: 10.1016/j.burns.2017.01.023. Epub 2017 Apr 12.

[53] Rajan V, Varghese B, van Leeuwen TG, Steenbergen W. Review of methodological developments in laser Doppler flowmetry. Lasers Med Sci. 2009 Mar;24(2):269-83. doi: 10.1007/s10103-007-0524-0. Epub 2008 Jan 31.

[54] Millet C, Roustit M, Blaise S, Cracowski JL. Comparison between laser speckle contrast imaging and laser Doppler imaging to assess skin blood flow in humans. Microvasc Res. 2011 Sep;82(2):147-51. doi: 10.1016/j.mvr.2011.06.006. Epub 2011 Jul 1.

[55] O'Doherty J, McNamara P, Clancy NT, Enfield JG, Leahy MJ. Comparison of instruments for investigation of microcirculatory blood flow and red blood cell concentration. J Biomed Opt. 2009 May-Jun;14(3):034025. doi: 10.1117/1.3149863. 
[56] Mirdell R, Farnebo S, Sjöberg F, Tesselaar E. Accuracy of laser speckle contrast imaging in the assessment of pediatric scald wounds. Burns. 2018 Feb;44(1):90-98. doi: 10.1016/j.burns.2017.06.010. Epub 2017 Aug 7

[57] Mirdell R, Farnebo S, Sjöberg F, Tesselaar E. Using blood flow pulsatility to improve the accuracy of Laser Speckle Contrast Imaging in the assessment of burns. Under review in Burns 2019.

[58] Lindahl F, Tesselaar E, Sjöberg F. Assessing paediatric scald injuries using Laser Speckle Contrast Imaging. Burns. 2013 Jun;39(4):662-6. doi:

10.1016/j.burns.2012.09.018. Epub 2012 Oct 23.

[59] Mirdell R, Farnebo S, Sjöberg F, Tesselaar E. Interobserver reliability of laser speckle contrast imaging in the assessment of burns. Burns. 2019 June 10.1016/j.burns.2019.01.011.

[60] Mirdell R, Iredahl F, Sjöberg F, Farnebo S, Tesselaar E. Microvascular blood flow in scalds in children and its relation to duration of wound healing: A study using laser speckle contrast imaging. Burns. 2016 May;42(3):648-54. doi: 10.1016/j.burns.2015.12.005.

[61] Heeman W, Steenbergen W, van Dam G, Boerma EC. Clinical applications of laser speckle contrast imaging: a review. J Biomed Opt. 2019 Aug;24(8):1-11. doi: 10.1117/1.JBO.24.8.080901.

[62] Chambers R. Vasomotion in the hemodynamics of the blood capillary circulation. Ann N Y Acad Sci. 1948 May 11;49(Art 4):549-52.

[63] Nilsson H, Aalkjaer C. Vasomotion: mechanisms and physiological importance. Mol Interv. 2003 Mar;3(2):79-89, 51.

[64] Aalkjær C, Boedtkjer D, Matchkov V. Vasomotion - what is currently thought? Acta Physiol (Oxf). 2011 Jul;202(3):253-69. doi: 10.1111/j.1748-1716.2011.02320.x. Epub 2011 May 27.

[65] Intaglietta M. Vasomotion and flowmotion: physiological mechanisms and clinical evidence. Vascular Medicine Review 1990;1:101-112.

[66] Eriksson S, Nilsson J, Sturesson C. Non-invasive imaging of microcirculation: a technology review. Med Devices (Auckl). 2014 Dec 9;7:445-52. doi: 10.2147/MDER.S51426.

[67] Jung F, Leithäuser B, Landgraf H, Jünger M, Franzeck U, Pries A, Sternitzky R, Franke RP, Forconi S, Ehrly AM. Laser Doppler flux measurement for the assessment of cutaneous microcirculatio--critical remarks. Clin Hemorheol Microcirc. 2013 Jan 1;55(4):411-6. doi: 10.3233/CH-131778. 
[68] Jones TW. Discovery that the veins of the bat's wing are endowed with rhythmical contractility and that onward flow of blood is accelerated by each contraction. Phil. Trans. Roy. Soc. Lond. 1852 Jan;142:131-136.

[69] Lal C, Unni SN. Correlation analysis of laser Doppler flowmetry signals: a potential non-invasive tool to assess microcirculatory changes in diabetes mellitus. Med Biol Eng Comput. 2015 Jun;53(6):557-66. doi: 10.1007/s11517-015-1266-y.

[70] Mirdell R. Lemstra-Idsardi AN, Farnebo S, Tesselaar E. The presence of synchronized perfusion dips in the microcirculation of the resting nail bed. Microvasc Res. 2019 Jan;121:71-81. doi: 10.1016/j.mvr.2018.10.004. Epub 2018 Oct 12.

[71] Neganova AY, Postnov DD, Jacobsen JC, Sosnovtseva O. Laser speckle analysis of retinal vascular dynamics. Biomed Opt Express. 2016 Mar 18;7(4):1375-84. doi: 10.1364/BOE.7.001375. eCollection 2016 Apr 1.

[72] Singh V, Devgan L, Bhat S, Milner SM. The pathogenesis of burn wound conversion. Ann Plast Surg. 2007 Jul;59(1):109-15.

[73] Salibian AA, Rosario ATD, Severo LAM, Nguyen L, Banyard DA, Toranto JD, Evans GRD, Widgerow AD. Current concepts on burn wound conversion-A review of recent advances in understanding the secondary progressions of burns. Burns. 2016 Aug;42(5):1025-1035. doi: 10.1016/j.burns.2015.11.007. Epub 2016 Jan 17.

[74] Yang Z. (ed). Phenomenon of Progressive Deepening in Burn Wounds. In: Chinese burn surgery. Springer Netherlands; 2015. p. 210. doi: 10.1007/978-94-017$8575-4$

[75] Zötterman J, Mirdell R, Horsten S, Farnebo S, Tesselaar E. Methodological concerns with laser speckle contrast imaging in clinical evaluation of microcirculation. PLoS One. 2017 Mar 30;12(3):e0174703. doi: 10.1371/journal.pone.0174703. eCollection 2017.

[76] Elawa S, Mirdell R, Tesselaar E, Farnebo S. The microvascular response in the skin to topical application of methyl nicotinate: Effect of concentration and variation between skin sites. Microvasc Res. 2019 Jul;124:54-60. doi:

10.1016/j.mvr.2019.03.002. Epub 2019 Mar 12.

[77] Yucel B, Coruh A, Deniz K. Salvaging the Zone of Stasis in Burns by Pentoxifylline: An Experimental Study in Rats. J Burn Care Res. 2019 Feb 20;40(2):211-219. doi: 10.1093/jbcr/irz005. 


\section{Appendix}

\section{A tutorial: how to create a ROI}

The reasoning behind region(s) of interest (ROI) creation has succinctly been described in the different papers included in the thesis 'Blood Flow Dynamics in Burns'. A comprehensive guide on the matter does not however exist. The following text is intended as a guide for the reader to learn about ROI creation and how to avoid common pitfalls. There is no literature on the subject and much of the content is based on the author's personal experience and indirect experience through less experienced LSCI-users. All experience of the author and details in the guide are based on the PeriCam PSI System (Perimed AB, Järfälla, Sweden).

\section{Basics about the perfusion images}

The images consist of motion of the chromophore hemoglobin which has a high reflection at $785 \mathrm{~nm}$. The more blood and the faster it moves, the higher the perfusion value will be. This is quantified on a scale, which is rather linear, and day-to-day reliability is guaranteed by using a calibration box regularly. In burns, the perfusion values vary between roughly 20 to 800 perfusion units (PU). To be able to form an opinion based on a quick glance, the same perfusion filter should always be used. The perfusion filter will decide which perfusion values are converted to which color. The recommended window is 0-500 PU, as this will differentiate the burn depths in a good way and make sure that deep burns always appear blue. All references to color in the appendix assume usage of the recommended window of 0-500 PU.

\section{Perfusion edges}

A normal burn will present with several edges within the burn. A perfusion image of this can be seen in appendix figure 1 . The first important edge to identify is the $1^{\text {st }}$ edge between uninjured skin/first degree burn and the superficial partial-thickness burn. In the early phase the patient will often have extensive first degree burns which cause a mild increase of perfusion in these areas, often in the range of 100-200 PU. These areas can however be identified as they are not very homogenous and often particularly spotty in their appearance. The aim is to look beyond this area and find the 
$1^{\text {st }}$ edge, where the first homogenous perfusion area is located. This area varies in size a lot but will always consist of a superficial or sometimes a very superficial partialthickness burn. Most of the time, the edge will be red/yellow in appearance, but can also be only yellow in appearance.

After the $1^{\text {st }}$ edge has been identified, further edges may be detected more centrally in the wound. These edges are often less sharp. The $2^{\text {nd }}$ edge corresponds to the onset of the zone of stasis. Sometimes this edge appears as a sharp demarcation, but most of the time as a gradual perfusion decrease over $0.5-3 \mathrm{~cm}$. This can be thought of as the $2^{\text {nd }}$ edge and it corresponds to areas of intermediate partial-thickness. If perfusion values are above $200 \mathrm{PU}$ on presentation (day 0-1) they will seldom convert to a zone of coagulation.

In some cases, a $3^{\text {rd }}$ edge can be seen. The $3^{\text {rd }}$ edge is typically found within a larger area of intermediate partial-thickness burns where the zone of stasis is close to becoming a coagulation zone. The $3^{\text {rd }}$ edge is often sharper than the $2^{\text {nd }}$ edge and encircles an area with blue to dark blue color. The clinical outcome of these areas often seems to depend on their size, as areas with a diameter $<2 \mathrm{~cm}$ often increase in perfusion regardless of a low initial value. If the area within the $3^{\text {rd }}$ edge has a diameter of at least $2 \mathrm{~cm}$ and a low enough perfusion, the wound will become a coagulation zone. 


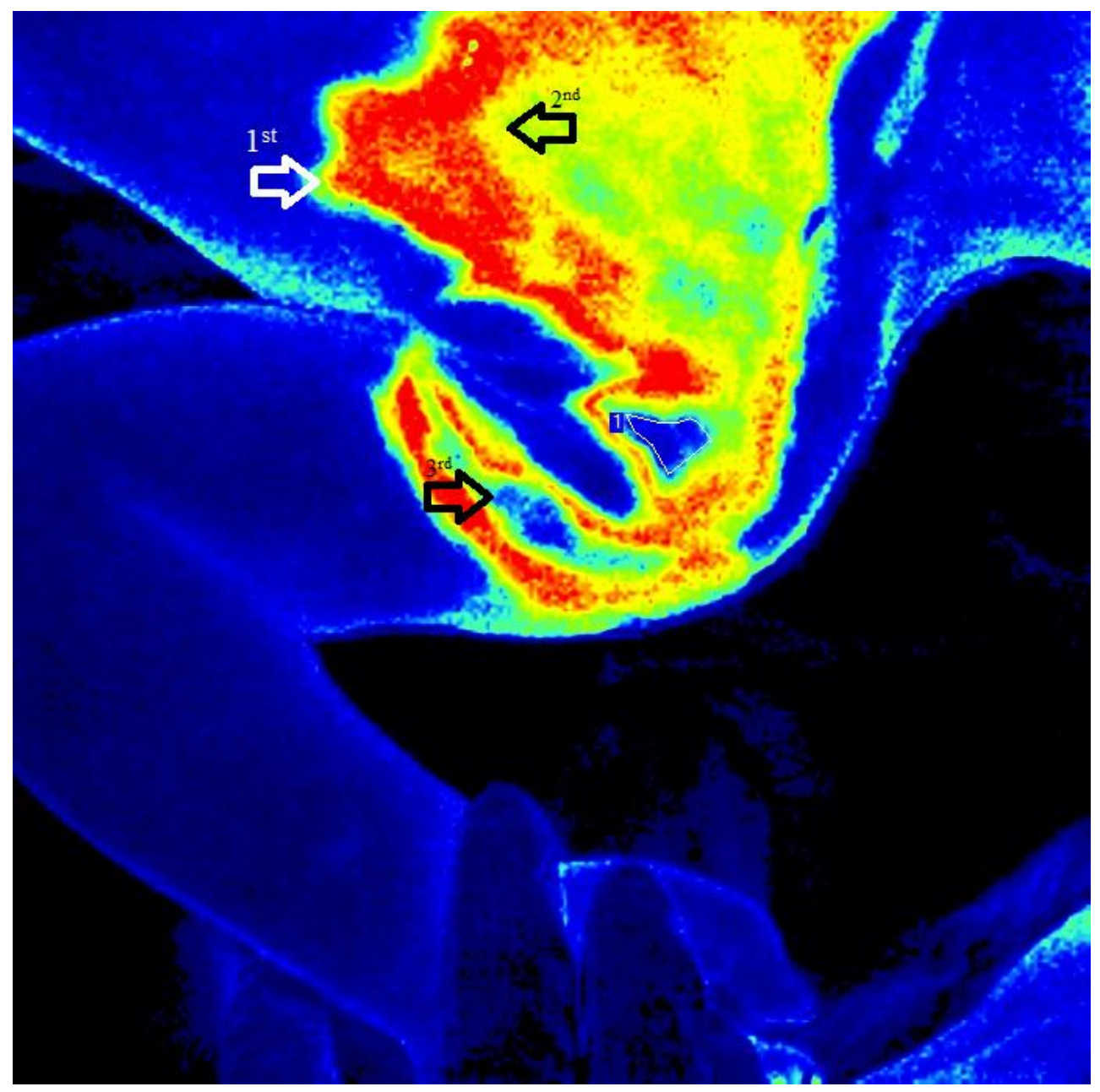

Appendix figure 1. A description of the different perfusion edges that can be found in burns. The $1^{\text {st }}$ edge can be found between superficial partial-thickness burns and uninjured skin or skin with only epidermal damage. The $2^{\text {nd }}$ edge occurs inside the superficial partial-thickness wound and corresponds to the onset of the zone of stasis. The $3^{\text {rd }}$ edge is inside the zone of stasis bordering to the start of the zone of coagulation. There is also a ROI placed centrally in the image which is located within the $3^{\text {rd }}$ edge of a scald that achieved spontaneous healing 20 days after injury.

Besides the previously described pattern of perfusion edges, there is one specific situation where perfusion edges are hard to correctly assess. This phenomenon seems rare and is associated with a good prognosis. The wound will appear with a spotty perfusion image, making it hard to understand which perfusion edge is which at first. The wound is usually a large scald and the perfusion image will show homogenous 
areas $(>2 \times 2 \mathrm{~cm})$ and stripes of different perfusion levels. The perfusion always ranges between yellow and red color, sometimes containing a little green. The logical conclusion would be that the yellow/green areas are intermediate partial-thickness burns if they are surrounded by a red perfusion area. However, in these specific cases the yellow/green perfusion areas often correspond to a very superficial burn, even though there is a clear $1^{\text {st }}$ edge. Instead of a single point of focus, as is often the case in the deeper scalds, the wound occurred through smaller splashes of hot liquid. This caused an uneven distribution of heat energy, explaining the perfusion pattern. It should be remembered that some of the low perfusion spots might contain deeper scalds, and that large areas which appear greenish should always be regarded with suspicion. Please see appendix figure 2 for an example of this.

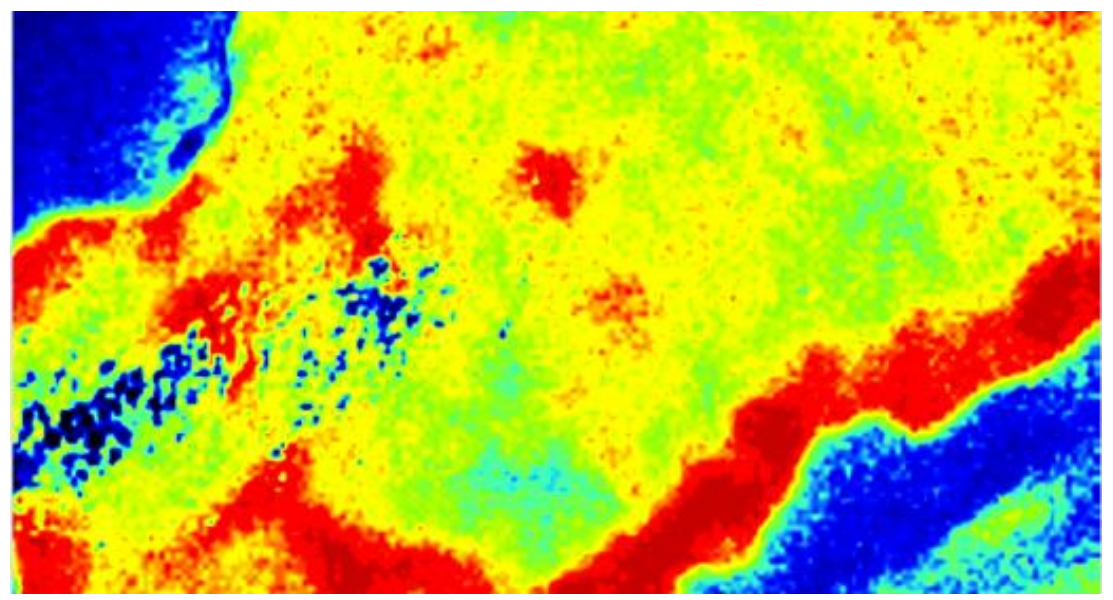

Appendix figure 2. Perfusion image of a scald with a patchy perfusion appearance. There is also a prominent specular reflection in the left side of the image. Several of the central areas have a reduced perfusion, suggestive of a deeper wound. However, many of them are not surrounded by superficial burns with a clear red area. There are also patchy areas of red between them without any clear borders.

The lack of large homogenous areas of superficial burn with high perfusion in combination with an unclear border pattern should alert the observer to the possibility that the central areas may be superficial too.

To realize where perfusion edges end and begin is crucial as a perfusion value alone does not have any meaning without a correct assessment of its surroundings. At the same time, the area of the ROI being investigated is also crucial as this can affect the healing potential. 


\section{Perfusion and healing potential}

Intact skin will always have a low perfusion because it is in a resting state. The most common perfusion is between 20-120 PU, this depends on the age of the patient but also on the measurement location. Additionally, perfusion will always show a false increase in thorax/abdominal areas due to respiratory artefacts.

The very superficial burns which heal within 3-4 days often do not have a maximal perfusion response, likely because the tissue damage is not extensive enough to create a large inflammatory response. They will generally present with 200-300 PU and appear yellow with the recommended perfusion filter. The best way to identify the very superficial burn is by looking at the edges, something which is important to remember.

The superficial partial-thickness burns, which heal between 5-11 days, will typically have maximal perfusion response in the area of 300-500 PU. They will appear red or have a spotty combination of red and yellow. These burns are dynamic in their perfusion and will increase after initial presentation reaching a peak 2-4 days after injury. Following the perfusion dynamics in these burns might therefore provide information of suspected healing time. The closest edge to this type of burn is often uninjured skin but sometimes there is a small area of very superficial burn between the superficial burn and the uninjured skin. More centrally in the burn, there can also be a transition zone towards a deeper or more superficial burn.

The intermediate partial-thickness burns, which heal between 12-20 days, have a perfusion between 150-250 PU. They will often have a spotty appearance with a combination of yellow and green. To be certain that the burn is of intermediate partialthickness, there should be a clear $2^{\text {nd }}$ edge surrounding the entire area. The area should also be quite large, preferably $>2 \times 2 \mathrm{~cm}$ and there should not be spots with higher perfusion in it, as this makes it more likely to be a very superficial burn. A certain tellsign is if there is a $3^{\text {rd }}$ edge present within the area. It does not matter whether the area with deep burn is very small or not, as its existence indicates that the surrounding area must be of intermediate partial-thickness. Please see appendix figure 3 for an example of an intermediate partial-thickness scald. 

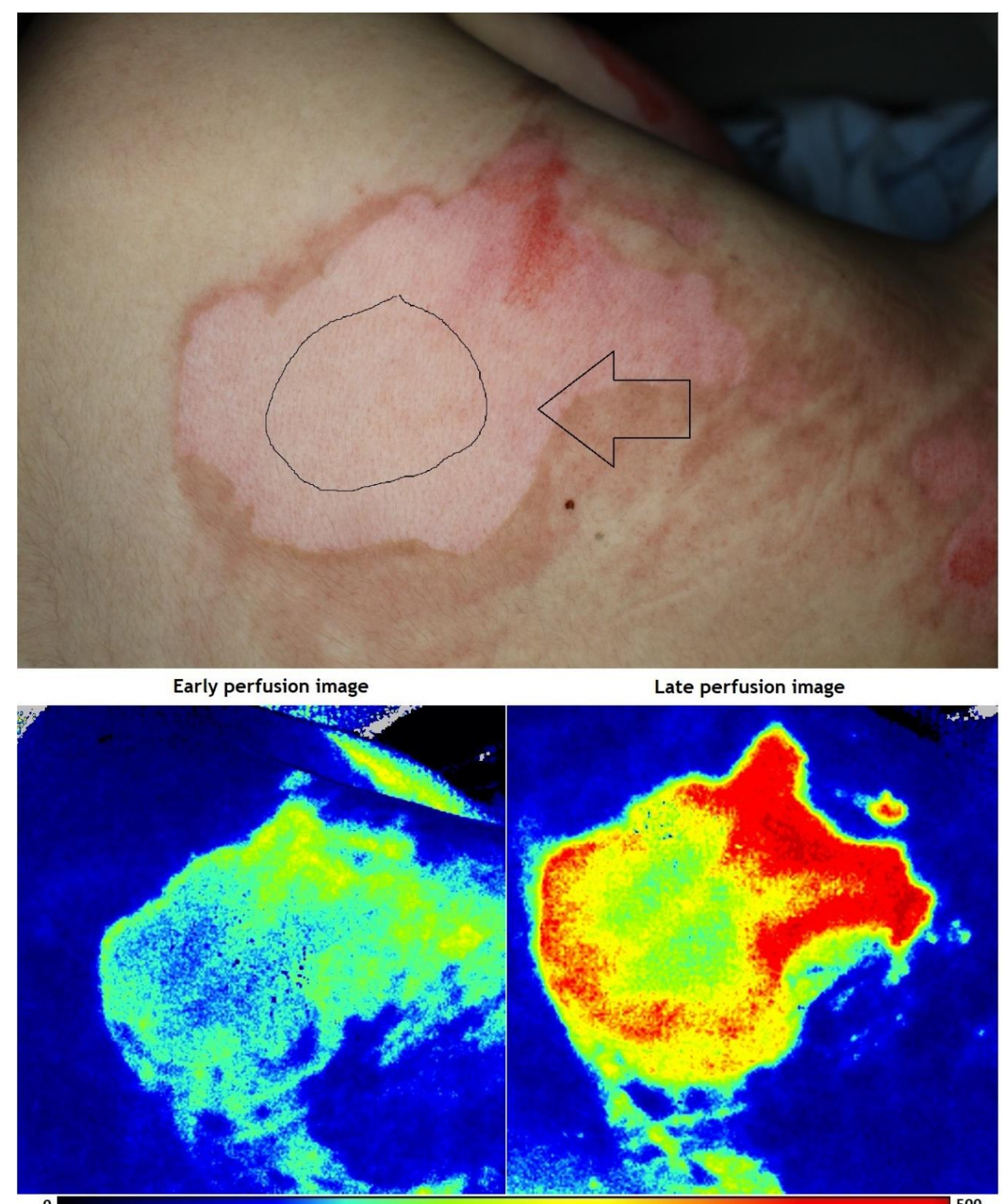

Appendix figure 3. Perfusion images and a cross-polarized image of a scald burn. The early perfusion image was captured 17 hours after injury and the late perfusion image 4 days after injury. The cross-polarized image was captured at the same time as the early perfusion image. The central wound healed within 14 days and should be considered as intermediate partial-thickness.

Based on the low perfusion in the first image, surgery was within the realm of possibilities. None of this was easy to observe in the normal cross-polarized image or clinically. In the late image on day 4 , the perfusion had greatly improved, and spontaneous healing was a certainty. Also notice how the borders have evolved between the two images and how much easier it is to identify the $1^{\text {st }}$ and $2^{\text {nd }}$ borders in the late perfusion image. 
The deep partial-thickness burns, which heal beyond 21 days and require surgery, will generally present with a perfusion between 50-200 PU. The span is quite large, and this also depends on the mechanism of the burn. A contact burn will do most of its damage to the dermis right away and the perfusion will be lower the first 48 hours after injury. In scalds, the vascular damage is more spread out through the dermis. Scalds are therefore often associated with burn wound conversion, where the scald deepens within 2-3 days after injury. The differences in perfusion depending on mechanism of injury make the perfusion span a bit larger for deep-partial thickness burns. These wounds do not have a spotty appearance, as vascular damage is extensive and homogenous from a macroscopic point of view. The color will range from blue with some green/tan mixed in and the deeper burns will appear dark blue/black. Appendix figure 4 shows a deep partial-thickness contact burn. 

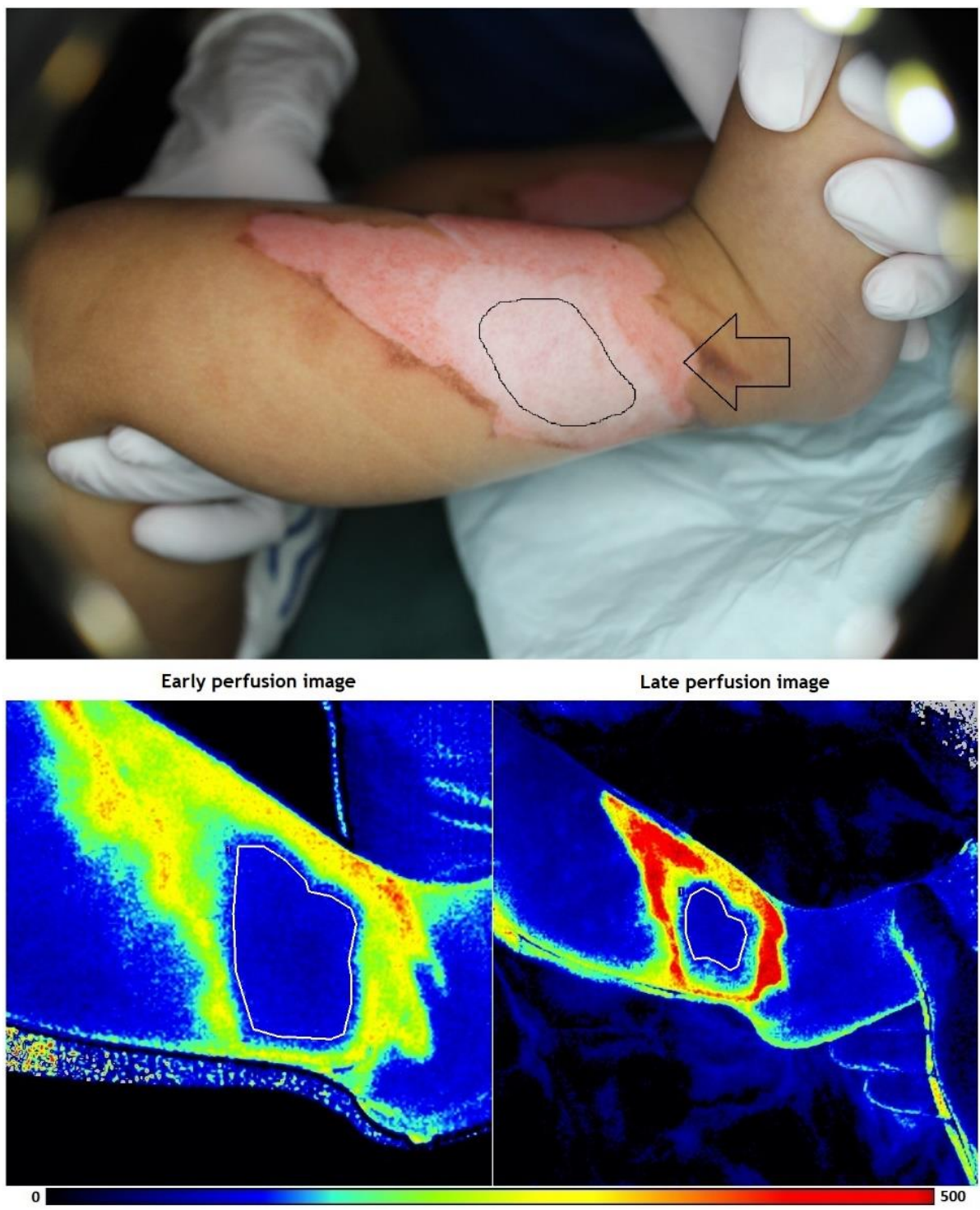

Appendix figure 4. Perfusion images and a cross-polarized image of a contact burn. The early perfusion image and the cross-polarized image was captured 19 hours after injury and the late perfusion image 4 days after injury. The central marked part is a typical example of a deep partialthickness burn surrounded by superficial partial-thickness burn. Notice the clear change from the early to the late perfusion image in the surrounding areas, and how the perfusion remained the same in the central area.

Contact burns behave differently when perfusion dynamics are measured, likely due to a clear tissue damage demarcation from the start, which stop contact burns from exhibiting the same degree of burn wound conversion so commonly observed in scalds. The low perfusion values combined with a whitish to red speckled color pattern makes this a clear-cut case for skin grafting in the eyes of the experienced observer. 
In some rare cases, patients present with areas that appear blue in the middle of an otherwise superficial burn. This is an area of uninjured skin that somehow got spared in the accident. In these cases, the edges will often be very sharp, like the $1^{\text {st }}$ edge between a superficial burn and uninjured skin. If the edges look reasonably sharp and if there is no surrounding area of intermediate partial thickness burn, the blue area which looks like a deep partial-thickness burn might be uninjured skin. This is an uncomfortable mistake to make, and the easiest way to avoid it is by looking at the patient before looking at the images. If the areas of uninjured skin have specific patterns it also needs to be regarded how the accident came to be, as it may be a sign of child abuse. Please see an example of this in appendix figure 5.

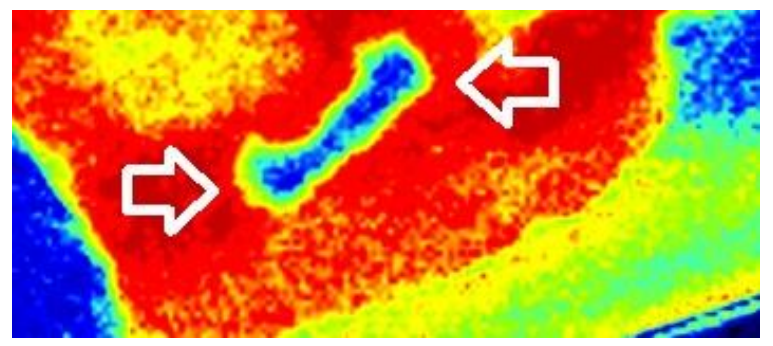

Appendix figure 5. Perfusion image of a wound where an area of intact skin has been spared. The area of interest is marked with two white arrows. Look at the borders of the area and how sharp they appear. This kind of border is clearly a $1^{\text {st }}$ border and not a $3^{\text {rd }}$.

\section{What constitutes a ROI?}

When a ROI is marked, it can often correspond to a larger area. For this reason, it is important to identify what constitutes a homogenous area. When this is done, the exact size and placement of the ROI will only affect the perfusion by a few PU, having no clinical impact on the assessment. This often means that the ROI can be used as a surrogate for an area in a different location. If a video recording of the perfusion is made, it is better to use a ROI that is much smaller as it makes it easier to deal with motion artefacts. The ROI is then assumed to reflect the perfusion of the entire area we want to investigate.

All different perfusion ranges that exist in the burn should be covered. It is therefore important to create the ROI needed to achieve this. In many cases, when the entire burn is superficial, 1-2 ROI is usually enough. Sometimes there will be several areas with lower perfusion. In these cases, an individual ROI should be created for 
each suspected area, as a surrogate ROI is not enough. In a typical patient with suspected surgical need, roughly 3-10 ROI should be investigated.

Another aspect that must be considered when marking is the time required to make a comprehensive analysis of all perfusion data. As previously mentioned, many areas will have the same or very similar perfusion dynamics. It is therefore important to find the areas with a meaningful difference. The easiest way to ensure this is to make use of oval or round ROI put in the middle of the different homogenous zones. When pulsatility measurements are used, this will ensure that small movement artefacts do not put the ROI outside of the intended area. This method also ensures that edge regions are not included which are often of a different depth and behave differently as they might be close to uninjured skin.

\section{Development of different methods for evaluation of perfusion images}

Previously when perfusion images from LDI-systems have been used, the dominating color has often been the deciding factor for depth assessment. This evaluation system has both pros and cons. It is easy to use, but in some cases in can be hard to decide which color is more prevalent and sometimes it may come down to slight guesswork. Particularly when perfusion is evaluated at different days, this method becomes observer dependent. A good example of this are the findings reported in [1], where different surgeons evaluated the same images in very different ways. However, all observers managed to produce very similar prefusion values. For this reason, using the actual perfusion numbers creates an objective value which is more suitable when evaluating perfusion images.

In [2] the early perfusion dynamics in scalds were described, and the conclusion was that surgical need of scalds could be evaluated based on these early changes [2]. In [3] we could create a formula which used the perfusion from the first day after injury and compared it to the perfusion day 3-4 after injury. This formula was very successful but had a serious drawback; it required 2 separate measurements to be used. However, we were also able to show that single measurements done day 3-4 were accurate for determining surgical need [3]. To find a method that would use the advantages of LSCI over LDI, a new approach had to be considered.

Vasomotion has for a long time been an interesting topic, but the actual use in a clinical setting has not been extensive. We have previously published findings regarding vasomotion in the nailbed of healthy test subjects [4], but vasomotion has so far seen little use in the area of burn diagnostics. In [5] a new formula was presented, where the perfusion was used in combination with the cardiac vasomotion to form a 
pulsatility measurement. We were able to show that pulsatility did not have the same dynamics as perfusion and that pulsatility can be used the same day as the injury occurred to determine surgical need.

The new method presented in [5] however introduces a new assessment issue. Previously, there were 1-10 images to choose from and with the new pulsatility method there were as many as 50-1000 images. How to select the correct images might seem a daunting task, but once some experience is attained within the subject, most observers will find the method straightforward.

\section{How to make a perfusion recording}

When recording images in a patient, the easiest method is to start a recording without time limit and to point the LSCI-camera towards the different burn wounds. The goal with this is to create a quick overview of the burn. Once this has been done, the next step is to review the image material. This should be done in conjunction with a quick clinical assessment. The main objective is to find areas of interest that the observer believes could be deep partial-thickness wounds. This evaluation should be done by looking at the color of the image and investigate if there are zones with lower perfusion anywhere in the wound. Heterogeneity in the perfusion might be a sign that there are deep parts. Due to time constraints, this kind of evaluation needs to be done in a quick manner, by simply looking at the color and quickly creating a ROI in select areas with low perfusion or simply a single ROI if the entire wound looks homogenous in perfusion.

Once this step has been done, each individual wound should be measured for a minimum of 4 seconds and for 8 seconds if there is any doubt about the depth of the burn. Areas which had low perfusion on the overview should always be measured for 8 seconds. In practice, this means that a typical pediatric patient with surgical need might need one to four 8 -second measurements before the entire perfusion scan is complete.

To make an 8-second measurement as presented in [5] there must be 42 consecutive images without any larger motion artefacts. When the recording is complete, potential movement artefacts therefore need to be assessed on the spot. The easiest way to accomplish this is by looking at the entire perfusion in the recording. Typically, it will resemble a jigsaw pattern (because of cardiac vasomotion). If there are any larger spikes present in the graph, these are likely caused by motion artefacts. If there is no 8-second window without motion artefacts a new recording of that area should be made. 
There are several pitfalls when recording perfusion and this will be a short description of the most common issues that can be encountered. These issues are intrinsic to LSCI as a method and do not have anything to do with software issues.

The distance between the camera and the measured tissue is of some importance. We have previously shown that the perfusion is not affected in a significant way when camera distance is kept between 12 and $35 \mathrm{~cm}$. There are however a few aspects which may have a large impact on the measured perfusion, and these are the following: angles, motion artefacts, specular reflections, shadows, and other sources of light.

Angles are important and an angle above $30^{\circ}$ will often cause an increased perfusion. This is because of the anatomical structure of the skin where there is a superficial vascular plexus and a deeper vascular plexus in the dermis. The reticular dermis below the superficial vascular plexus has a low capillary density in comparison. A steep angle will therefore increase the viewed thickness of the superficial vascular plexus and will increase its contribution to the perfusion signal.

Motion artefacts will always cause a positive increase in perfusion because any movement of the target tissue causes additional movement of the blood. The LSCI will always record the actual movement of the blood within the vessels, but also the movement of the vessels containing blood. If motion artefacts are present, there will often be blurriness in the perfusion image. These two aspects in combination can be used to identify perfusion images with motion artefacts for the experienced observer (see appendix figure 6).

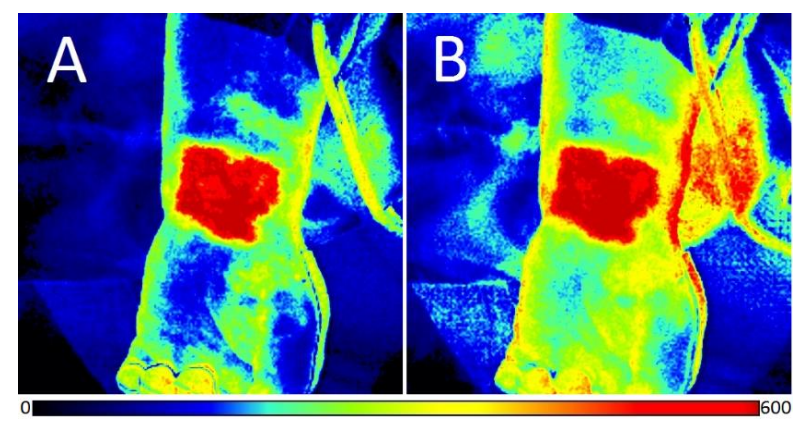

Appendix figure 6. Perfusion image of a movement artefact. Image A to the left is captured only seconds before image B on the right, where a slight movement artefact has occurred. Look at the general increase of perfusion of the entire image, particularly in parts of the image that should be recorded as low or no perfusion such as the underlay. Also observe the sharp perfusion increase at the radial side coming from a slight pronation motion. 
Specular reflections will instead create a perfusion image with a reduced perfusion. This issue arises because of overexposure. Since the reflective surface is static, this will be interpreted by the software as high contrast which is equal to low perfusion. For the issue to arise, we need to have a wet and shiny surface and burns have these two qualities in abundance. An example is shown in appendix figure 7.
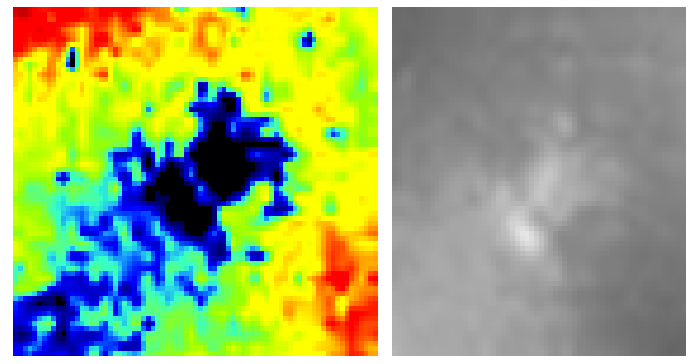

Appendix figure 7. Perfusion image of a specular reflection to the left with the intensity image from the same area to the right. Specular reflections often have the appearance of holes from a shotgun shell, with a central area with many artefacts and fewer but sharp artefacts in the directly surrounding area. Also look at the intensity image and clear traces of over exposure will be evident.

The first time I ever observed a specular reflection was when I looked at the perfusion image of a 6 year child and to my horror I saw this blue/black blob in the middle of the forehead, which I had realized might mean he would need to undergo extensive surgery, in the face no less. Once I moved the camera to a slightly different angle to get a better image, the area had moved. I continued to experiment with this and at a steep enough angle (around $20-30^{\circ}$ ) the reflection was no longer visible at all. I learned later that the polarization filter for our camera had come loose and was a few degrees from its intended position.

When the polarization filter is working, specular reflections are not that common, however. In wounds with visible fluid, a small degree of specular reflections may be present. These will look like holes from a shotgun shell with sharp areas where the perfusion drops 200-300 PU within just a few pixels. The perfusion value from these pixels will often be negative. The best course of action to avoid the issue is to make sure the wound is reasonably dry when the recording is done. If this is not possible, several measurements and a slight angle of no more than $15-20^{\circ}$ can be used to reduce the level of specular reflections. 
Another issue is the presence of shadows. These arise because the laser and camera are placed with a slight angle between them. Since the LSCI-camera receives very little light from the shaded areas, they will be underexposed. This means that the contrast will be very poor, and the software will interpret this as areas of high perfusion. These shadows never present a problem in routine usage but may sometimes confuse inexperienced LSCI-users who have not seen shadows before.

Another technical issue is the presence of other light sources in the room where the LSCI-camera is used. Current commercially available LSCI-cameras uses a diode laser at $785 \mathrm{~nm}$. Modern lights produce mostly visible light, but old lamps typically have a very wide spectrum, with a substantial part of the energy in the near-infrared spectrum of 2500-750 nm. This type of lamp sometimes exists in older operating theatres, and one should be aware of the risk of interference with the measurements.

\section{To the reader}

I hope this guide has been interesting to read and that it will help improve your understanding of LSCI as a method for early burn diagnostics. Remember that this is only a short guide and to truly understand the different aspects, firsthand experience is a must. LSCI is a tool and a perfusion/pulsatility value alone should never be the basis of a surgical decision. 
[1] Mirdell R, Farnebo S, Sjöberg F, Tesselaar E. Interobserver reliability of laser speckle contrast imaging in the assessment of burns. Burns. 2019 June 10.1016/j.burns.2019.01.011.

[2] Mirdell R, Iredahl F, Sjöberg F, Farnebo S, Tesselaar E. Microvascular blood flow in scalds in children and its relation to duration of wound healing: A study using laser speckle contrast imaging. Burns. 2016 May;42(3):648-54. doi:

10.1016/j.burns.2015.12.005.

[3] Mirdell R, Farnebo S, Sjöberg F, Tesselaar E. Accuracy of laser speckle contrast imaging in the assessment of pediatric scald wounds. Burns. 2018 Feb;44(1):90-98. doi: 10.1016/j.burns.2017.06.010. Epub 2017 Aug 7.

[4] Mirdell R. Lemstra-Idsardi AN, Farnebo S, Tesselaar E. The presence of synchronized perfusion dips in the microcirculation of the resting nail bed. Microvasc Res. 2019 Jan;121:71-81. doi: 10.1016/j.mvr.2018.10.004. Epub 2018 Oct 12.

[5] Mirdell R, Farnebo S, Sjöberg F, Tesselaar E. Using blood flow pulsatility to improve the accuracy of Laser Speckle Contrast Imaging in the assessment of burns. Under review in Burns 2019. 



\section{Papers}

The papers associated with this thesis have been removed for copyright reasons. For more details about these see:

http://urn.kb.se/resolve?urn=urn:nbn:se:liu:diva-162216 


\section{FACULTY OF MEDICINE AND HEALTH SCIENCES}

Linköping University Medical Dissertation No. 1720, 2019 Department of Clinical and Experimental Medicine

Linköping University

SE-581 83 Linköping, Sweden

www.liu.se 